\title{
Past, Present and Future Approaches to the Prevention and Treatment of Respiratory Syncytial Virus Infection in Children
}

\author{
Eric A. F. Simões · Louis Bont · Paolo Manzoni · Brigitte Fauroux • \\ Bosco Paes · Josep Figueras-Aloy · Paul A. Checchia · Xavier Carbonell-Estrany
}

Received: December 18, 2017 / Published online: February 22, 2018

(c) The Author(s) 2018. This article is an open access publication

\section{ABSTRACT}

Introduction: The REGAL (RSV Evidence - A Geographical Archive of the Literature) series has provided a comprehensive review of the published evidence in the field of respiratory syncytial virus (RSV) in Western countries over the last 20 years. This seventh and final

Enhanced content To view enhanced content for this article go to http://www.medengine.com/Redeem/ F6E4F06044E2A44B.

Electronic supplementary material The online version of this article (https://doi.org/10.1007/s40121018-0188-z) contains supplementary material, which is available to authorized users.

\section{E. A. F. Simões}

Center for Global Health, Colorado School of Public Health, University of Colorado School of Medicine, Aurora, CO, USA

L. Bont

University Medical Center Utrecht, Utrecht, The Netherlands

L. Bont · P. Manzoni

ReSViNET (Respiratory Syncytial Virus Network), Utrecht, The Netherlands

\section{P. Manzoni}

Neonatology and NICU, Sant'Anna Hospital, Turin, Italy

B. Fauroux

Necker University Hospital and Paris 5 University, Paris, France publication covers the past, present and future approaches to the prevention and treatment of RSV infection among infants and children.

Methods: A systematic review was undertaken of publications between January 1, 1995 and December 31, 2017 across PubMed, Embase and The Cochrane Library. Studies reporting data on the effectiveness and tolerability of prophylactic and therapeutic agents for RSV infection were included. Study quality and strength of evidence (SOE) were graded using recognized criteria. A further nonsystematic search of the published literature and Clinicaltrials.gov on antiviral therapies and RSV vaccines currently in development was also undertaken.

\section{B. Paes}

Department of Paediatrics (Neonatal Division), McMaster University, Hamilton, Canada

\section{J. Figueras-Aloy}

Hospital Clínic, Catedràtic de Pediatria, Universitat de Barcelona, Barcelona, Spain

\section{P. A. Checchia}

Baylor College of Medicine, Texas Children's Hospital Houston, Houston, TX, USA

X. Carbonell-Estrany $(\square)$

Hospital Clinic, Institut d'Investigacions

Biomediques August Pi Suñer (IDIBAPS), Barcelona, Spain

e-mail: carbonell@comb.cat 
Results: The systematic review identified 1441 studies of which 161 were included. Management of RSV remains centered around prophylaxis with the monoclonal antibody palivizumab, which has proven effective in reducing RSV hospitalization (RSVH) in preterm infants $<36$ weeks' gestational age $(72 \%$ reduction), children with bronchopulmonary dysplasia $(65 \%$ reduction), and infants with hemodynamically significant congenital heart disease (53\% reduction) (high SOE). Palivizumab has also shown to be effective in reducing recurrent wheezing following RSVH (high SOE). Treatment of RSV with ribavirin has conflicting success (moderate SOE). Antibodies with increased potency and extended half-life are currently entering phase 3 trials. There are approximately 15 RSV vaccines in clinical development targeting the infant directly or indirectly via the mother.

Conclusion: Palivizumab remains the only product licensed for RSV prophylaxis, and only available for high-risk infants. For the general population, there are several promising vaccines and monoclonal antibodies in various stages of clinical development, with the aim to significantly reduce the global healthcare impact of this common viral infection.

Funding: AbbVie.

Keywords: Antibody; Antiviral; IGIV; Motavizumab; Respiratory syncytial virus; Ribavirin; Palivizumab; Prophylaxis; Special populations; Vaccine

\section{INTRODUCTION}

Respiratory syncytial virus (RSV)-associated lower respiratory tract infection (LRTI) imposes a substantial medical and financial burden on pediatric health services and families worldwide [1-3]. It is known to infect almost all children by 2 years of age [4], with the risk of severe illness increased in certain well-recognized highrisk groups, such as preterm infants with or without chronic lung disease (CLD)/bronchopulmonary disease (BPD) and those with congenital heart disease (CHD) [5-7]. Growing evidence suggests that a number of other underlying medical conditions are also associated with an increased risk of severe RSV infection [8], including Down syndrome [9-12], cystic fibrosis [8, 11, 13-15], congenital malformations [11, 16], cancer [17], and the immunocompromised [11, 18]. The risk of RSV hospitalization (RSVH) decreases with increasing age, peaking in the first few months of life $[3,19-21]$, though older children are still susceptible to severe disease [22]. Several studies have also demonstrated that exposure to RSV infection in the first 3 years of life is associated with long-term respiratory problems, including recurrent wheezing and asthma [23-25], and possibly allergic sensitization [26], which may persist into early adulthood [24, 27-29].

Treatment of RSV LRTI is currently limited by a lack of effective antiviral agents-with the possible exception of ribavirin in certain populations-and is primarily supportive, including the use of supplemental oxygen, mechanical ventilation, and fluid replacement therapy. Comprehensive hygiene measures are efficacious and cost-effective in preventing the spread of RSV, and should always be advocated as a prophylactic measure. Although vaccine candidates have been in clinical evaluation for nearly 50 years, none, to date, have reached licensing. Palivizumab, a humanized monoclonal antibody, is currently the only intervention licensed for the prevention of severe RSV disease. However, its use is limited to certain subsets of high-risk infants, including the preterm population and those with CLD/BPD and CHD. The World Health Organization (WHO) has recognized the importance of the unmet medical need of the management of respiratory viruses, and in 2012 launched the BRaVe (Battle against Respiratory Viruses) initiative [30]. This initiative provides a framework to help direct and facilitate research into respiratory viral infections [30]. A crucial component of undertaking any new research into RSV is to gain a full understanding of the current evidence base.

The REGAL (RSV Evidence - A Geographical Archive of the Literature) series defines our current understanding of RSV as well as, importantly, identifying gaps in our knowledge and future areas of research. This paper, which represents the final one of a series of seven 
publications covering a range of topics on RSV, identifies and describes the main approaches to the prevention and treatment of RSV disease among infants and children which have been used over the last 20 years, and discusses promising drugs and RSV vaccines on the horizon.

\section{METHODS}

\section{Study Objective}

REGAL addressed seven specific research questions, covering: overall epidemiology [3], prematurity [5], CLD/BPD [6], CHD [7], long-term respiratory morbidity [29], other high risk groups (e.g., Down syndrome) [8, 9], and-the focus of the current paper-past, present and future approaches to the prevention and treatment of RSV. This paper has two specific aims. First, to systematically review the evidence for the following therapeutic interventions in the pediatric population over the last 20 years: RSV immunoglobulin (RSV-IGIV); palivizumab; motavizumab; and ribavirin. Secondly, to undertake a non-systematic review to identify and evaluate promising new therapies and vaccines for RSV which will be available in the near future.

\section{Literature Searches}

The systematic review of current and past therapies was undertaken using the same broad methodology as for the other REGAL publications, which has been described in detail elsewhere [3]. To identify relevant studies, we used the following general terms, combined with Medical Subject Headings (MeSH), in MEDLINE (PubMed), EMBASE and the Cochrane Library: ["RSV" OR "respiratory syncytial virus" OR "lower respiratory tract infection" OR "bronchiolitis" OR "acute respiratory tract infection" OR "LRTI" OR "ARTI"] AND ["palivizumab" OR "Synagis" OR "motavizumab" OR "immunoprophylax" munoglobulin" OR "immune globulin" OR "IVIG" OR "RespiGam" OR "ribavirin"] AND limits: "human, child (birth to 18 years)". No language limits were set on the database searches, with the caveat that an English translation of at least the abstract had to be available. All original studies and selected systematic reviews and meta-analyses were included in the review. As per the ambit of REGAL, studies conducted in Western countries were included, which were defined as the United States, Canada, and Europe (including Turkey and the Russian Federation). Selected studies of particular relevance or importance outside the Western countries were also included to supplement the evidence base. The systematic literature search included studies published between January 1, 1995 and December 31, 2017, with other relevant studies, published during the drafting of the manuscript, also included, as identified by the authors.

The non-systematic search to identify promising antivirals and RSV vaccines that are currently in development was undertaken in MEDLINE (PubMed), EMBASE, the Cochrane Library and ClinicalTrials.gov, supplemented by publications identified by the authors. No restrictions were placed on included publications.

\section{Evaluation of Data}

As part of the systematic review, studies were graded using a modified version of the Oxford Centre for Evidence-Based Medicine (CEBM) Levels of Evidence [31, 32]. Meta-analyses are graded as level 1 by the CEBM, but since such studies were excluded from our review, we considered level 1 to be randomized controlled trials (RCTs) and level 2 to be observational studies (with dramatic effect). Level 3 (nonrandomized controlled cohort/follow-up study) and level 4 evidence (case-series, case-control studies, or historically controlled studies) were as per the CEBM definitions. For RCTs, a quality assessment of each citation was carried out using the five-point ( $1=$ low quality; $5=$ high quality) Jadad Scale [33]. Risk of bias was assessed using the Cochrane Collaboration's tool for RCTs [34] and the RTI Item Bank (score of 
$1=$ very high risk of bias; score of $12=$ very low risk of bias) for observational studies [35].

\section{Compliance with Ethics Guidelines}

The analysis in this article is based on previously published studies and does not involve any new studies of human or animal subjects performed by any of the authors.

\section{RESULTS}

\section{Past and Present Preventative and Therapeutic Interventions}

The systematic review identified 2032 publications. After excluding duplicates $(-605)$ and screening of titles $(-1240)$, abstracts $(-40)$ and full papers $(-0), 147$ relevant studies remained (Fig. 1). Supplemented by 14 references identified from other sources, a grand total of 161 studies were included in the review. The vast majority of studies involved palivizumab (120

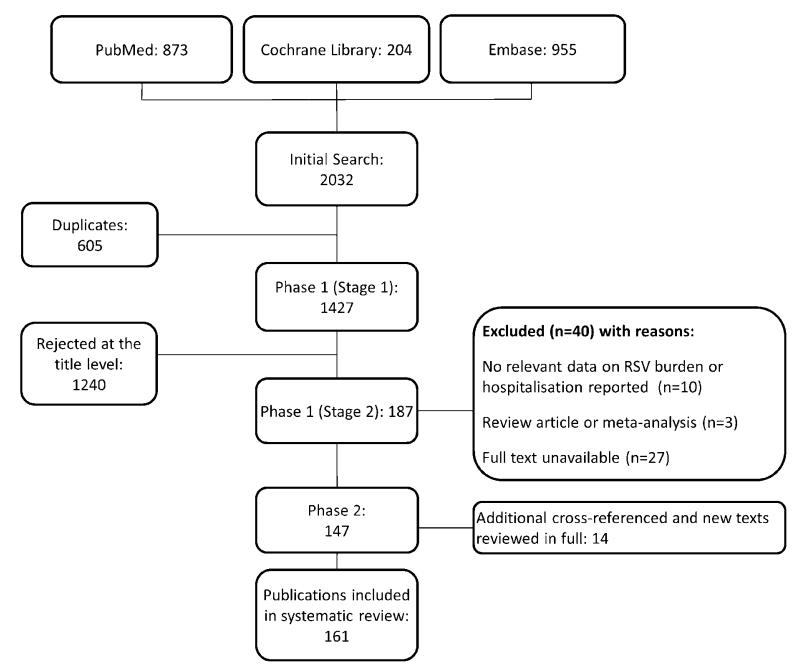

Fig. 1 PRISMA flow diagram. Treatment and prevention strategies for RSV over the last 20 years. $R S V$ respiratory syncytial virus. References were screened for inclusion in two Phases. Phase I screening was split into two Stages, Stage 1-based on title and, for those meeting the inclusion criteria, Stage 2-based on abstract. Those references retained after Phase 1 were assessed based on the full paper in Phase 2 studies), with fewer studies available for RSVIGIV (11), motavizumab (4), and ribavirin (19). Some studies included more than one intervention. Due to space restriction, only the key studies for palivizumab, RSV-IGIV and ribavirin have been cited and summarized in the text (defined as: RCTs, prospective studies, postmarketing studies, international registries, and large retrospective studies for disease areas with limited prospective data; all studies with a minimum of 100 subjects). Non-specific treatment and supportive measures, such as oxygen, bronchodilators, etc., are the subject of many Cochrane reviews [36-48] and Society Guidelines $[49,50]$ and are not discussed further. Hygienic measures are also not discussed in the text. Data extraction tables for all the studies identified in this systematic review, however, are available in the online supplementary material.

\section{Prevention of RSVH}

\section{RSV-IGIV}

RSV hyper immunoglobulin (RSV-IGIV), a polyclonal human intravenous (IV) antibody preparation, was the first successful prophylactic modality developed for preventing severe RSV in infants and children under the age of 2 years. In the seminal The National Institute of Allergy and Infectious Diseases (NIAID) trial [51, 52], in 249 infants and young children with BPD, CHD or prematurity ( $\leq 35$ weeks' gestational age; wGA) alone, RSV-IGIV was shown to significantly reduce lower respiratory infection (LRI; 7 vs. 20 episodes in the control group), RSVHs (6 vs. 18), days in the hospital (43 vs. 128 ), and stays in the intensive care unit (ICU; 1 vs. 34 days, $P=0.05)$ in children administered at a high dose $(750 \mathrm{mg} / \mathrm{kg}$ body weight) compared to controls. However, because five of six deaths occurred in children with heart disease, further trials were carried out in children with either prematurity (PREVENT trial) [53] or with CHD (CARDIAC trial) [54].

In 1996, RSV-IGIV became the first agent approved by the US Food and Drug Administration (FDA) for the prevention of RSV in preterm infants $<36$ wGA and infants with BPD 
Table 1 Incidence of RSVH and hospital resource use in children with BPD and/or history of prematurity ( $\leq 35$ wGA) in the PREVENT trial [53]

\begin{tabular}{|c|c|c|c|c|}
\hline & $\begin{array}{l}\text { RSV-IGIV } \\
(n=250)\end{array}$ & $\begin{array}{l}\text { Placebo } \\
(n=260)\end{array}$ & Reduction & $P$ value \\
\hline Incidence of RSVH (\%) & 8.0 & 13.5 & $41 \%$ & 0.047 \\
\hline Total days of hospitalization per 100 children & 60 & 129 & $53 \%$ & 0.045 \\
\hline $\begin{array}{l}\text { Total days of RSVH requiring increased supplemental oxygen per } \\
100 \text { children }\end{array}$ & 34 & 85 & $60 \%$ & 0.007 \\
\hline $\begin{array}{l}\text { Number of hospital days with moderate or severe LRI (LRI } \\
\text { score } \geq 3^{\text {a }} \text { ) per } 100 \text { children }\end{array}$ & 49 & 106 & $54 \%$ & 0.049 \\
\hline $\begin{array}{l}\text { Total days of ICU or mechanical ventilation for RSV per } 100 \\
\text { children }\end{array}$ & 28 & 50 & - & - \\
\hline
\end{tabular}

$I C U$ intensive care unit, $L R I$ lower respiratory infection/illness, $R S V$-IGIV respiratory syncytial virus intravenous immunoglobulin, $R S V H$ respiratory syncytial virus hospitalization

${ }^{a}$ LRI score: $0=$ no respiratory illness/infection; $1=$ upper respiratory tract illness (URI); $2=$ mild LRI; $3=$ moderate LRI; $4=$ severe LRI; $5=$ mechanical ventilation. The LRI score was calculated as the mode of the following three $(\mathrm{A}, \mathrm{B}, \mathrm{C})$ component scores, or the mean if there was no mode: A. Oxygen saturation $-0=$ Baseline value (no URI), $1=$ Baseline value (URI), $2=$ Decrease $<5 \%, 3=$ Decrease $5-10 \%, 4=$ Decrease $>10 \%, 5=$ Mechanical ventilation; B. Respiratory rate $-0=$ Baseline value (no URI), $1=$ Baseline value (URI), $2=$ Increase $1-14 / \mathrm{min}, 3=$ Increase $15-30 / \mathrm{min}, 4=\mathrm{In}$ crease $>30 / \mathrm{min}, 5=$ Mechanical ventilation; C. Retractions, Wheezing, Crackles $-0=$ No change (no URI), $1=$ Minimal, $2=$ Mild, $3=$ Moderate, $4=$ Severe, $5=$ Mechanical ventilation [51]. Values for oxygen saturation, respiratory rate, and pulmonary findings were compared with baseline values on usual oxygen flow [51]

aged $<24$ months. The pivotal study was the PREVENT trial [53], in which children received RSV-IGIV $750 \mathrm{mg} / \mathrm{kg}$ every 30 days for a maximum of 5 infusions. RSV-IGIV prophylaxis was associated with a $41 \%$ reduction in RSVH and a $53 \%$ reduction in total days of hospitalization per 100 children versus placebo (Table 1) [53]. Another study demonstrated that RSV-IGIV is effective in preventing severe RSV disease in preterm infants, with similar results to the PREVENT trial [55]. In a long-term follow-up study of children with CLD/BPD who had received RSV-IGIV 7-10 years previously in the seminal NIAID trial [51], these children were shown to have better lung function $(P=0.02)$ and less atopy (15 vs. $50 \% ; P<0.04)$ compared with matched children who had not received prophylaxis in that trial [26].

Despite the successful use of RSV-IGIV in preterm infants, there were safety concerns and an apparent lack of efficacy in some patient populations. The RCT undertaken in children with CHD (CARDIAC trial) failed to achieve its primary efficacy endpoint of reduced RSVH, being effective only in those infants aged $<6$ months [54]. There was also a significantly higher frequency of cyanotic episodes and poor outcomes after surgery among children with cyanotic CHD in the RSV-IGIV group than in the control group (28 vs. $8.5 \%$; $P=0.009$ ). This was ascribed to hyperviscosity that occurred with the administration of $750 \mathrm{mg} / \mathrm{kg}$ of the RSV-IGIV [54]. Such data led to RSV-IGIV being indicated only for premature infants $\leq 32$ wGA and those with CLD [56]. RSV-IGIV was eventually voluntarily withdrawn from the market in 2003 following the successful licensing of the first monoclonal antibody for RSV (palivizumab) in 1998. RSV-IGIV had demonstrated the potential of passive immunoprophylaxis in effectively and safely preventing RSVH, and the focus of research was directed towards the development of monoclonal antibodies. 


\section{Palivizumab}

Following the demonstration that RSV-IGIV could successfully prevent RSV LRI and RSVH $[51,53]$, MedImmune and other vaccine manufacturers started developing monoclonal antibodies against RSV, with the hope of finding a simpler and safer route for prophylaxis. Of the three monoclonal antibodies developed [57-59], palivizumab was the only one that was licensed, in 1998. Palivizumab is a humanized monoclonal antibody administered via intramuscular (IM) injection at $15 \mathrm{mg} / \mathrm{kg}$ monthly during the RSV season, and is licensed for the prevention of severe RSV in high-risk children, including: children born at $<35$ wGA and $<6$ months at the onset of the RSV season; children $<2$ years requiring treatment for BPD within the last 6 months; and children $<2$ years of age with hemodynamically significant CHD (HS-CHD). The key study results for palivizumab, stratified by patient population, are summarized below.

Prematurity With or Without CLD/ BPD Support for the efficacy of palivizumab in reducing RSVH rates in preterm infants with or without CLD/BPD comes from a number of RCTs and prospective studies conducted in the USA, Canada, and Europe [60-77]. In the registration study, IMpact-RSV [61], prophylaxis with palivizumab resulted in a $55 \%$ reduction in RSVH versus placebo in children with prematurity $(\leq 35$ wGA $)$ or BPD (4.8 vs. $10.6 \%$, respectively; $P<0.001)$. Significant reductions were observed in both children with BPD (39\% reduction, $P=0.038$ ) and preterm children without BPD $(78 \%$ reduction, $P<0.001)$. For infants born at $<32 \mathrm{wGA}$, palivizumab reduced the RSVH rate by $47 \%(P=0.003)$ and in infants born at $32-35$ wGA by $80 \%(P=0.002)$. Palivizumab also reduced the rate of admission to ICU ( 1.3 vs. $3.0 \% ; P=0.026)$, the incidence of all respiratory hospitalizations (16 vs. 22\%; $P=0.008)$, and the total respiratory-related hospital days per 100 children (124 vs. 180 days; $P=0.004)$ versus placebo [61]. In a subgroup efficacy analysis of the cohort of preterm infants without BPD, palivizumab consistently reduced RSVH (64.5-100\%) versus placebo across all 11 gestational age groups evaluated [78].
In the Spanish FLIP-2 study [66], the incidence of RSVH was significantly lower in infants born at 32-35 wGA who received prophylaxis with palivizumab than in untreated infants (1.3 vs. $4.1 \% ; P<0.001)$. The Palivizumab Outcomes Registry was established in 2000 to prospectively collect data on any child receiving palivizumab prophylaxis at any of the registry sites within the USA [77]. RSVH rates across the 4 seasons (2000-2004) for infants who received palivizumab prophylaxis ranged from 1.1 to $4.5 \%$ for infants born at $<32$ wGA and $0.2-1.6 \%$ for infants born at 32-35 wGA [77]. In 2002, a meta-analysis of all studies to date, which compared studies with and without palivizumab prophylaxis, illustrated a weighted mean RSVH rate of $10.2 \%$ in infants 29-32 wGA without CLD who had not received prophylaxis compared to $2.0 \%$ in those who had received prophylaxis [79]. Corresponding rates in those born 32-35 wGA without CLD were 9.8 and $1.5 \%$, respectively. In those with CLD/BPD, the weighted mean RSVH rate in children $<2$ years old was $17.9 \%$ in those who had not received prophylaxis compared to $5.6 \%$ in those who had received it [79].

Further real-world experience comes from a comparative study that examined the dosing regimens, compliance, and outcomes of preterm infants who received palivizumab within the Canadian Registry of Palivizumab (CARESS) [76]. Data for the 2006-2011 RSV seasons were compared for preterm infants born $\leq 32 \mathrm{wGA}$ without underlying medical disorders to that of infants born 33-35 wGA. RSVH rates for infants of both $\leq 32$ and 33-35 wGA following prophylaxis were found to be similar at 1.5 and $1.4 \%$, respectively, and were lower than similar groups in the treated arm of the IMpact-RSV Study (5.8 and $1.8 \%$, respectively) [61, 76]. Overall, the weighted mean for RSVH for palivizumab recipients versus untreated premature infants $(\leq 35 \mathrm{wGA})$ in the prospective, comparative studies identified $[61,64,65,72]$ was 3 vs. $9.5 \%$, respectively, (68\% relative reduction; range: 64-100\%) (Table 2). Stratified by wGA, palivizumab was associated with $62 \%(58-80 \%)$ reduction in RSVH in $<29$ wGA infants $[65,78]$, $75 \%(75-79 \%)$ in $29-32$ wGA infants $[65,78]$, and $71 \%(68-82 \%)$ in $32-35$ wGA infants 


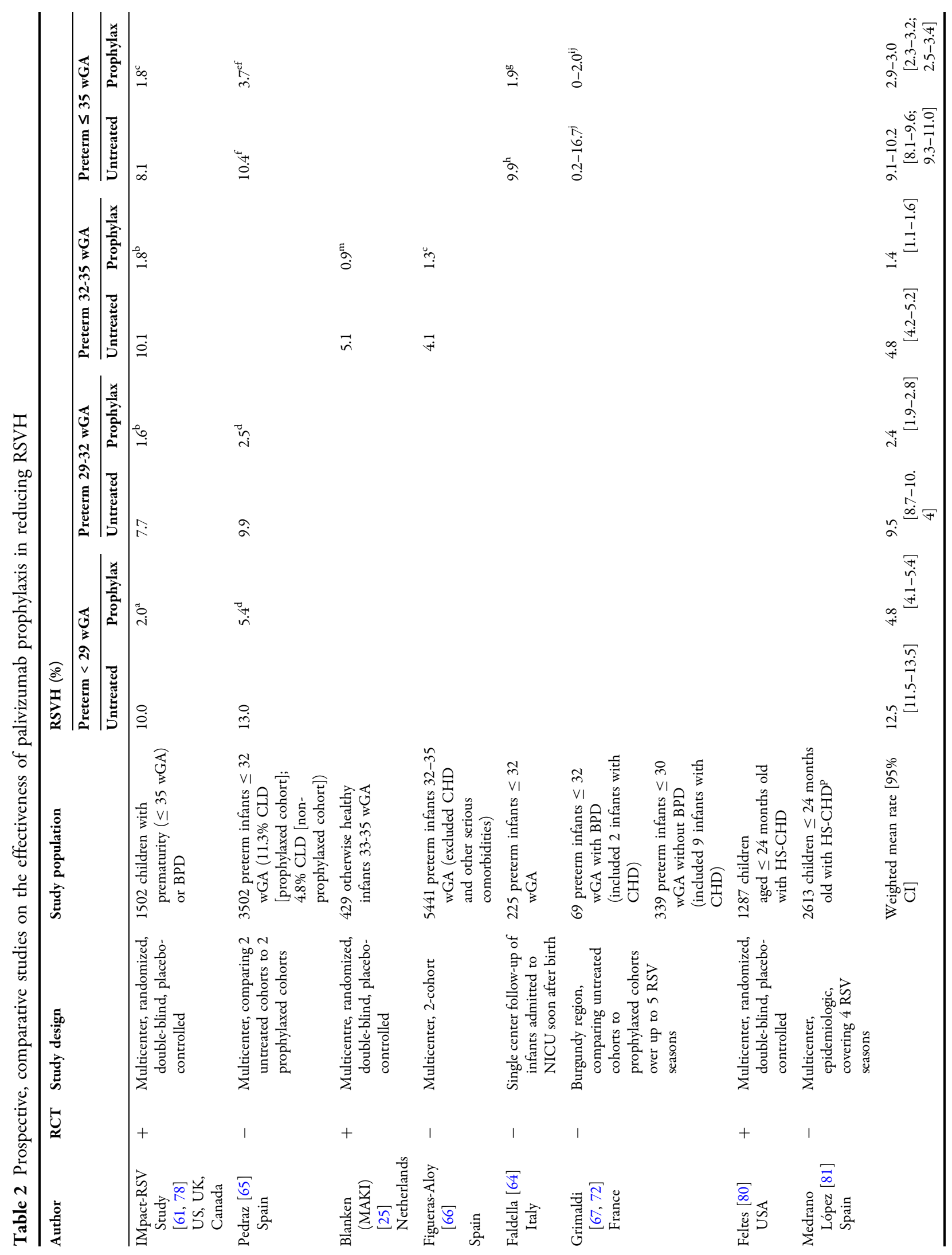




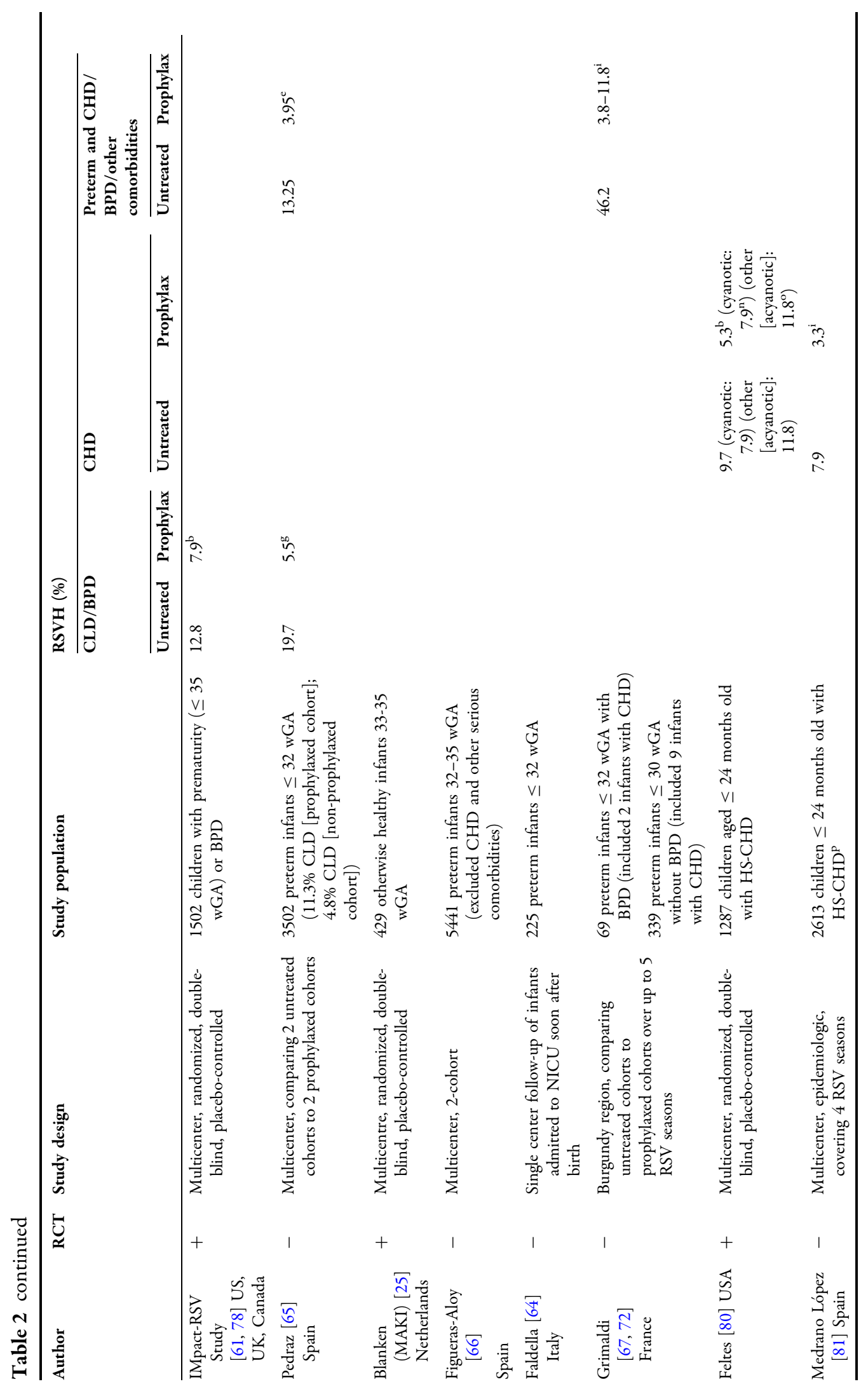




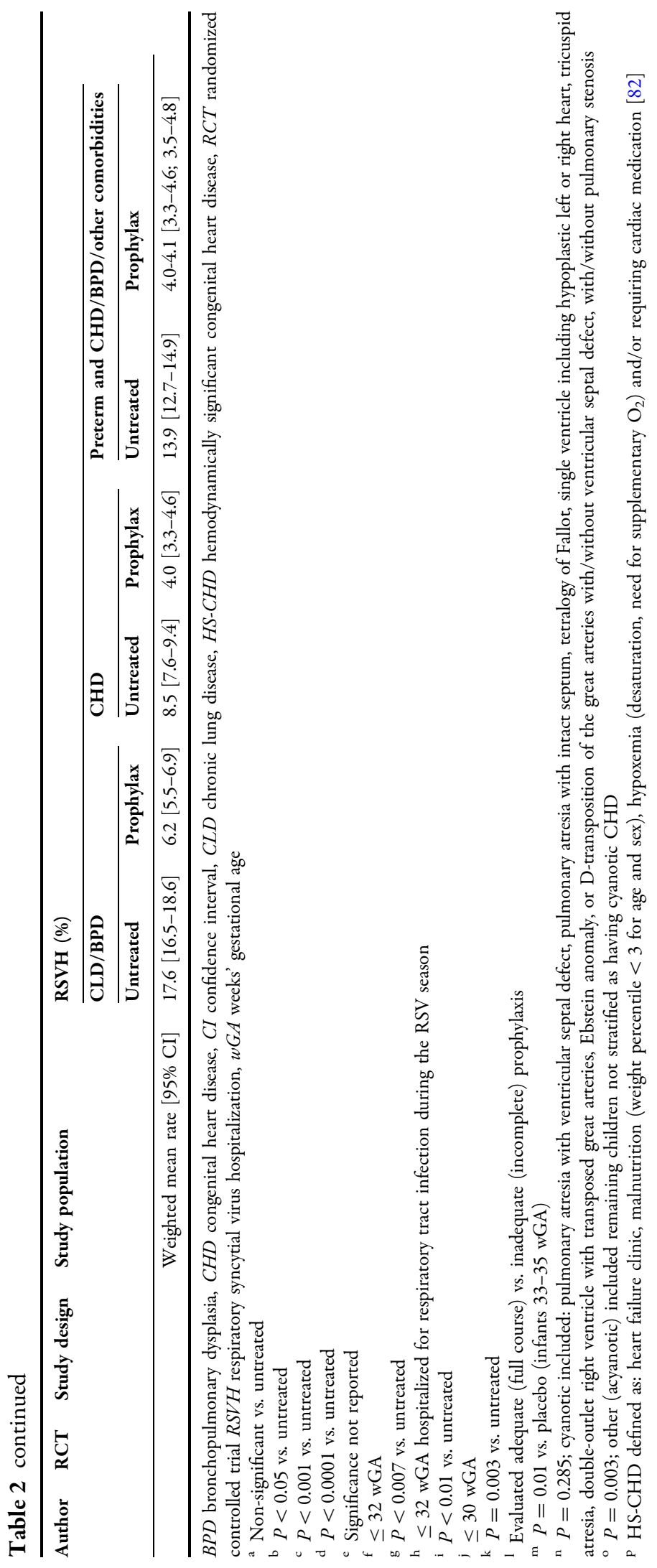


$[25,61,66]$. For infants with CLD/BPD, the mean weighted RSVH rate was $6.2 \%$ in palivizumab recipients versus $17.6 \%$ in untreated infants (65\% relative reduction; range $38-72 \%$ ) $[61,65]$. A recently published study using propensity score weighted regression analysis has shown that, when adjusted for the fact that prophylaxis is most routinely offered to those with risk factors for RSVH, palivizumab was shown to have an efficacy of $58 \%$ for preventing RSVH in infants $\leq 1$ year [60]. This is in line with the pivotal IMpact-RSV trial [61].

Congenital Heart Disease In 2003, Feltes et al. [80] published the results of their large RCT involving 1287 children with HS-CHD (defined as patients with cyanotic CHD, single ventricle physiology, or those with acyanotic CHD who required medical therapy). Palivizumab prophylaxis resulted in a $45 \%$ reduction in $\mathrm{RSVH}$ versus placebo (5.3 vs. 9.7\%, respectively; $P=0.003)$. In addition, children receiving palivizumab had significantly fewer total days of RSVH per 100 children (57.4 days palivizumab vs. 129 days placebo; $P=0.03$ ) and RSV hospital days with increased oxygen requirement per 100 children (27.9 vs. 101.5 days, respectively; $P=0.014$ ) [80]. Furthermore, unlike RSV-IGIV, it was safe in both infants and children with and without cyanotic heart disease [54], which led to its licensing in the US, Europe and many countries of the world for preventing severe RSV in infants and children with CHD.

Further evidence supporting the use of palivizumab in children with CHD comes from two non-comparative, prospective studies [67, 81], and from post-marketing observational studies from the United States [13, 83], Germany [84], and Canada $[85,86]$. The Palivizumab Outcomes Registry observed a cumulative RSVH rate of $1.9 \%$ among 1500 infants and children with CHD who received prophylaxis between 2000 and 2004 [83]. Among infants and children with cyanotic (29\%) and acyanotic (71\%) $\mathrm{CHD}$, hospitalization rates were 2.6 and $1.6 \%$, respectively. More detailed follow-up information on diagnosis was available for the 2002-2003 and 2003-2004 seasons, which showed that $44.1 \%$ had HS-CHD (as diagnosed by a healthcare practitioner), with patent ductus arteriosus (21.5\%), ventricle septal defect (16.7\%), and atrial septal defect (11.4\%) being the three most common diagnoses (Table 3) [83]. More recent data from CARESS suggest that children in their second year with HS-CHD, who remain unstable, are as equally at risk for RSVH $(1.7 \%)$ as infants in their first year (2.3\%) and merit prophylaxis [85]. This study used a more refined definition of HS-CHD, including those with uncorrected or palliated cyanotic CHD or acyanotic CHD associated with documented pulmonary hypertension (systolic pulmonary arterial pressure $\geq 40 \mathrm{mmHg}$ ) and/or a requirement for daily medication to manage congestive heart failure $[85,87]$. These criteria intentionally exclude patients with uncomplicated or insignificant CHD and are consistent with those from the pivotal study by Feltes et al. in 2003 [80, 87]. The overall weighted mean for palivizumab recipients versus untreated infants with HS-CHD in the prospective, comparative studies identified $[80,81]$ was 4.0 vs. $8.5 \%$, respectively, $(53 \%$ relative reduction; range 45-58\%) (Table 2).

Down Syndrome The medical needs for the prevention of RSVH in infants and children with Down syndrome are high [8-11], and there is growing clinical evidence to support the use of palivizumab in this population. In CARESS, RSVH rates in children with Down syndrome receiving palivizumab have been found to be low [88-91]. Yi et al. [89] compared hospitalization rates due to respiratory tract infection in 532 children with Down syndrome aged $<2$ years who received palivizumab during the RSV season in the CARESS registry (2005-2012) with a similar, untreated cohort of 233 children with Down syndrome from the Netherlands (2003-2005) [9]. In total, 31 children were hospitalized for RSV (23 untreated and 8 treated), and palivizumab prophylaxis was associated with a 3.6-fold (72\%) decrease in RSVH [89]. Four untreated children versus none of the treated group needed intensive care or respiratory support, and the mean number of days of oxygen treatment was significantly higher in the untreated group (19 vs. 2 days, respectively; $P<0.001)$. In a further post hoc analysis, 83 and $50 \%$ of RSVHs occurred within 
Table 3 Diagnosis and care of subjects with CHD in the Palivizumab Outcomes Registry 2002-2004 $(n=1101)$ [83]

\begin{tabular}{ll}
\hline $\mathrm{HS}-\mathrm{CHD}, n(\%)^{\mathrm{a}}$ & 485 \\
& $(44.1 \%)$
\end{tabular}

Primary diagnosis, $n$ (\%)

Patent ductus arteriosus 237

Ventricular septal defect

184

Atrial septal defect 126

Single ventricle (including hypoplastic left or 67 (6.1) right ventricle)

Tetralogy of Fallot

Atrioventricular canal defect (endocardial cushion defect)

Pulmonary stenosis

Coarctation of the aorta

Heart murmur ${ }^{\mathrm{b}}$

Transposition of the great arteries

Pulmonic atresia with ventricular septal defect

Aortic stenosis

Tricuspid atresia

Peripheral pulmonic stenosis ${ }^{\mathrm{b}}$

Truncus arteriosus ${ }^{\mathrm{b}}$

Double-outlet right ventricular with transposed great arteries

Pulmonary atresia with the intact septum

Ebstein's anomaly

Other 160

Current status of cardiac defect, $n$ (\%)

Uncorrected, no surgery planned

Uncorrected, surgery planned for future
Table 3 continued

\begin{tabular}{lc}
\hline HS-CHD, $\boldsymbol{n ( \% ) ^ { \mathbf { a } }}$ & $\begin{array}{l}\mathbf{4 8 5} \\
\mathbf{( 4 4 . 1 \% )}\end{array}$ \\
\hline Partially corrected & 207 \\
& $(18.8)$ \\
Fully corrected with residual effect & $84(7.6)$ \\
Fully corrected with no residual effect & 224 \\
& $(20.3)$ \\
Resolved without surgery & b \\
Unknown $^{\mathrm{b}}$ & $57(8.3)$ \\
Other & $79(11.5)$ \\
\hline
\end{tabular}

$H S-C H D$ hemodynamically significant congenital heart disease

${ }^{a}$ Diagnosis of HS-CHD was at the health care practitioner's discretion and independent from the primary diagnosis

b Data available only for 2003-2004 season $(n=688)$

the first year of the child's life in untreated and treated groups, respectively [89].

Cystic Fibrosis Evidence for the use of palivizumab in children with cystic fibrosis is relatively limited and inconclusive as to its usefulness. A retrospective study by Giebels et al. [15] reported no RSVHs in 35 young children $(80 \%<1$ year $)$ with cystic fibrosis who received palivizumab, and 3 confirmed RSVHs in 40 children $(73 \%<1$ year) with cystic fibrosis who were non-recipients (3 additional acute respiratory illnesses were also reported in the control group, but were not tested for RSV). Further information on the use of palivizumab for prevention of RSV in children with cystic fibrosis comes from international registries, including CARESS [90, 92] and the Palivizumab Outcomes Registry [93]. In the latter registry, there were no RSVHs in 91 children with cystic fibrosis who received palivizumab [93]. Other studies have also shown potentially positive effects of palivizumab, but overall inconclusive results, perhaps due to being underpowered [94, 95]. A recent systematic review of the safety and efficacy of palivizumab 
in infants and children with cystic fibrosis, which included 10 studies (6 cohort studies, 2 before-and-after studies, 1 cross-sectional study, and 1 RCT) involving 3891 patients with cystic fibrosis, did not provide unequivocal support for palivizumab in this population [96]. This was because of study limitations (before-after study design, low RSVH rate, etc.) for the most part and non-comparability of studies [96].

Other Significant Underlying Medical Conditions Some information is available on palivizumab use in infants and children with other significant underlying medical conditions, including those with neuromuscular disease and congenital airway anomalies [90, 91, 97-100]. In a post hoc sub-analysis of CARESS, the RSVH rate in children receiving palivizumab varied from 0.78 to $11.8 \%$, depending on the underlying medical condition (Table 4) [90]. Further data come from a recent prospective, multicenter, international cohort study that assessed the outcomes of 14,468 palivizumab recipients within CARESS and the Torino-Verona Italian Registry over the 2002-2014 RSV seasons [91]. Infants with neuromuscular disorders (7.88\%), airway anomalies

Table 4 RSVH rates in children with significant underlying medical disorders who received palivizumab in CARESS (2006-2010) [90]

\begin{tabular}{ll}
\hline $\begin{array}{l}\text { Underlying medical } \\
\text { disorder }\end{array}$ & $\begin{array}{l}\text { RSV hospitalization rate } \\
(\%)\end{array}$ \\
\hline Cardiac $(n=22)$ & 4.55 \\
Pulmonary $(n=127)$ & 1.73 \\
Neuromuscular $(n=78)$ & 6.90 \\
Other $(n=163)$ & 0.78 \\
Multiple $(n=57)$ & 2.01 \\
Immunocompromised & 11.8 \\
$\quad\left(n=17^{\mathrm{a}}\right)$ & \\
Airway anomalies $(n=178)$ & 2.70 \\
Down syndrome $(n=193)$ & 1.84 \\
Cystic fibrosis $(n=117)$ & 1.14 \\
\hline
\end{tabular}

${ }^{\text {a }}$ Includes one child with HIV
(5.95\%), BPD (4.75\%) and HS-CHD (4.10\%) were found to have higher incidences of RSVH than preterm infants born $\leq 35$ completed wGA $(2.37 \%)$. There were, however, no significant differences in regard to hospital length of stay, rates of ICU admission, or need for mechanical ventilation among the different groups of palivizumab-treated patients. It is not known whether the higher RSVH rates in the infants with severe underlying comorbidities related to inadequate palivizumab dosing protocols or to a specific increased RSVH risk inherent in these infants. The study also included 56 immunocompromised infants, 3 of whom had human immunodeficiency virus (HIV), in which no RSVHs were reported [91].

Safety Palivizumab was shown to be well-tolerated in the RCTs, with adverse events (AEs) similar to those reported for placebo [61, 80]. Real-world experience has confirmed the good safety profile of palivizumab, with low rates of serious adverse events (SAEs) reported, including in children with complex medical disorders [101-103]. Chen et al. [101] reported that the overall number of SAEs found in infants [63.1\% preterm infants $\leq 35 \mathrm{wGA}$ and $36.9 \%$ children aged $<2$ years with comorbidities (HS-CHD $11.1 \%$, BPD $7.5 \%$, complex underlying medical conditions $18.3 \%$ )] enrolled into CARESS was low. Six patients $(0.05 \%)$ experienced a total of 14 possibly- or probably-related SAEs (mainly hypersensitivity reactions) for an incidence of 2.8 per 10,000 patient-months [101]. In a phase 4 post-marketing study, Bonnet et al. [102] reported that palivizumab was not associated with an increase in infection or arrhythmia, or overall primary SAEs (infection, arrhythmia, or death) in children with HS-CHD.

Guidelines For certain groups of high-risk infants, including preterm infants with and without CLD/BPD and infants and children with HS-CHD, palivizumab has proven to be an effective and well-tolerated preventive strategy for RSVH. However, driven primarily by cost-benefit considerations, most national guidelines have restricted the use of palivizumab to sub-populations of the highest-risk children [104-111]. The American Academy of 
Pediatrics (AAP) 2014 policy statement $[104,112]$ recommends that only preterm infants born $<29^{\circ}$ wGA and $<1$ year at the season start date, infants in the first year of life with CLD of prematurity $\left(<32^{\circ}\right.$ wGA and a requirement for $>21 \%$ oxygen for $\geq 28$ days after birth) or those in the second year of life requiring medical support for CLD during the 6-month period before the start of the second RSV season, and infants with HS-CHD and $<1$ year at the season start date, are eligible for palivizumab prophylaxis. The evidence behind these recommendations, however, is not always clear, and many countries use earlier guidelines that rely on identification of risk factors to guide prophylaxis [108, 109]. Other high-risk groups, such as Down syndrome, are very rarely addressed in the various guidelines [113], despite evidence to suggest a beneficial or protective role for palivizumab in these children.

\section{Motavizumab}

Motavizumab was a second generation humanized monoclonal antibody derived from palivizumab. The expectation was that motavizumab would provide increased efficacy after demonstrating 10-fold greater activity in preclinical studies [114], whilst maintaining the good safety profile of palivizumab. The safety and efficacy of motavizumab as a prophylactic treatment for RSV infection was evaluated in two pivotal RCTs [87, 115]. Carbonell-Estrany et al. [115] assessed safety and RSVH in 6635 preterm infants aged $\leq 6$ months at enrolment or children aged $\leq 24$ months with CLD who received either palivizumab or motavizumab at a dose of $15 \mathrm{mg} / \mathrm{kg}$ once a month for 5 months. Motavizumab recipients had a $26 \%$ relative reduction in RSVH compared with palivizumab recipients, achieving non-inferiority. Further analyses showed that motavizumab was superior to palivizumab for reduction of RSV-specific, outpatient medically-attended LRTIs (50\% relative reduction). AEs were similar between treatments, although cutaneous events were more frequently reported in the motavizumab group (7.2 vs. $5.1 \%$ ) [115]. In a subsequent study, Feltes et al. [87] compared the safety and tolerability of motavizumab and palivizumab in
1236 children with CHD aged $\leq 24$ months Again, despite the overall safety profiles being similar, skin rashes were observed more frequently in motavizumab recipients (19.3 vs. $16.2 \%)$. In terms of efficacy of motavizumab, results were similar to those reported by Carbonell-Estrany et al. [115], with an observed $25 \%$ relative reduction in the incidence of RSVH and $51 \%$ relative reduction in the RSV outpatient medically-attended LRTI rate compared with palivizumab [87]. Finally, a RCT of motavizumab in healthy aboriginal American infants, conducted between 2004 and 2007, in which 1417 received motavizumab and 710 placebo, demonstrated an $87 \%$ relative reduction in RSVH in the motavizumab group [116]. Hypersensitivity events were more common in the motavizumab arm $(208 / 1417 ; 14.7 \%)$ than in the placebo arm $(87 / 710 ; 12.3 \% ; P=0.14)$, about twice the rate as that in the pivotal trial (7.2 and 5.1\%, respectively) [115]. Interestingly, antidrug antibodies were found in only $0.4 \%$ (3/ 717) of tested motavizumab recipients in this trial [116] compared to $1.8 \%(58 / 1227)$ in the pivotal trial [115].

In 2010, the FDA rejected the license application for motavizumab, primarily due to concerns over a lack of greater efficacy, increased hypersensitivity reactions relative to palivizumab, and the generalizability of the results, since non-inferiority was not reached in the sub-population of subjects from the northern hemisphere [114]. Recent findings have also indicated that motavizumab had no significant effect on RSV viral load or duration or severity of RSVH versus placebo when used in a treatment setting [117].

Prevention of Long-Term Outcomes with Antibodies Severe RSV LRTI has been associated with long-term respiratory problems, including recurrent wheezing and asthma, and possibly allergic sensitization later in life [25, 27-29]. The first long-term follow-up study of RSV prevention was in infants with BPD/CLD who had received RSV-IGIV 7-10 years earlier, which illustrated improved lung function among those who had received RSV-IGIV compared to controls [26]. It was hypothesized by the authors that RSV primarily causes direct 
pulmonary epithelial damage and local immunologic alterations in the lungs, leading to long-term airway hyper-responsiveness and wheezing [26]. Subsequently, a study examined the role of preventing RSV LRI with palivizumab in Europe and Canada [118]. In this prospective, multicenter, double-cohort study, the incidences of recurrent wheezing and physiciandiagnosed recurrent wheezing were significantly lower in 191 palivizumab-treated subjects (13 and 8\%, respectively) compared with all 230 untreated subjects $(26 \%, P=0.001$ and $16 \%, P=0.011$, respectively) and with 154 patients in the subgroup not hospitalized for RSV LRTI (23\%, $P=0.022$ and $16 \%, P=0.027$, respectively) [118]. In a subsequent analysis, this reduction in wheezing frequency was only seen in those children who did not have an atopic family history [119]. A third study, from Japan, was initiated soon after in which the outcomes of 349 infants born at 33-35 wGA without CLD who received palivizumab prophylaxis in the first 6 months of life were compared to 95 infants who did not receive prophylaxis [23]. At the 3-year follow-up, physician-diagnosed recurrent wheezing was observed in 6.4 and $18.9 \%$ of the infants in the two groups, respectively; this was significant after adjustment for differences in risk factors between the groups $(P<0.001)$ [23]. At the 6-year follow-up, there was no difference in atopic asthma between the two groups (15.3 and $18.2 \%$ in the treated and untreated groups, respectively; $P=0.57$ ) [24]. On the other hand, there was a significant difference in physiciandiagnosed recurrent wheezing (15.3 vs. $31.6 \%$, respectively; $P=0.003$ ) [24]. In this study, contrary to the European-Canadian study [119], significant differences were found only for recurrent wheezing in those with a family history of allergy within the Intention To Treat (all enrolled) analysis, the per protocol (those completing 6-year follow-up) analysis, and in those investigated for atopy (the atopic asthma population) [24].

A study (MAKI) investigating the pathogenesis of recurrent wheeze after RSV infection randomized otherwise healthy preterm infants born at 33-35 wGA to either monthly palivizumab injections (214 infants) or placebo (215 infants) during the RSV season [25]. Palivizumab treatment was shown to result in a relative reduction of $61 \%$ [95\% confidence interval (CI) 56-65] in the total number of wheezing days during the first year of life [930 of 53,075 days in the RSV group (1.8\%) vs. 2309 of 51,726 days (4.5\%) in the placebo group] [25]. In contrast to the findings of the previous trials with palivizumab [24, 119], the MAKI study found that palivizumab reduced wheezing in the first year of life in children born at 33-35 wGA regardless of whether there was a family history of atopy [25].

Finally, in a recent RCT of the long-term effects of RSV prevention with motavizumab in aboriginal American infants, despite those that received motavizumab $(n=1417)$ showing an $87 \%$ relative reduction in RSVH versus placebo $(n=710)$, there was no effect on rates of medically attended wheezing in children aged 1-3 years [116]. This study is at odds with the other RCTs from the US and Netherlands $[25,26]$, as well as the observational studies in Europe, Canada, and Japan [23, 24, 118, 119]. It is possible that differences in genetic makeup, or family history of asthma, or the low rates of recurrent wheezing in the aboriginal American populations studied may have accounted for the differences in outcome [120]. Another major difference is that the motavizumab trial involved both term and preterm infants [116], whereas the other studies involved only preterm infants $[25,26]$. The 6-year follow-up study of the Dutch MAKI trial will shed light on the association in preterm infants.

\section{Treatment of RSV LRTI}

There are very limited treatment options available for RSV infection in children. Ribavirin was approved in 1986 for aerosol treatment of RSV infection in infants and children in the United States; however, it is infrequently prescribed and mainly limited to immunocompromised infants. Ribavirin has been shown in one study to reduce the incidence of airway reactivity in previously healthy children if given early $[121,122]$, though not in another study [123]. It has also been shown to reduce the risk of progression from URTI to LRTI and all-cause mortality in RSV-positive allo-hematopoietic stem 
cell transplantation (HSCT) patients ranging from 3 to 70 years of age [124]. Ribavirin has been tested in combination with RSV-IGIV and palivizumab with generally positive results $[17,125,126]$. However, convincing data supporting its use as a treatment for children with RSV are lacking, and toxicity is a concern [123, 127-136]. Furthermore, multivariate analyses demonstrated that ribavirin treatment was associated with an increase in duration of hospital stay $[128,137]$. Based on available data, ribavirin is not recommended in the current AAP guidelines on the diagnosis, management and prevention of bronchiolitis [104].

\section{Future Approaches}

\section{Advances in RSV Vaccine Development}

Considering that the vast majority $(>70 \%)$ of RSVHs are in children with no underlying medical conditions [3], there remains a significant unmet need for efficacious and cost-effective preventive interventions against RSV [138]. Over the last 60 years, intense research has focused on understanding the pathogenesis of RSV infections and immunity to this infectious virus [139]. The first attempt to produce an RSV vaccine was made in the 1960s, but the formalin-inactivated, alum-precipitated RSV vaccine failed to protect children when they were naturally infected with RSV, and resulted in severe consequences in the vaccinated children that has influenced subsequent investigations in this area to the present day [140]. Numerous vaccine candidates have been developed using a broad range of approaches in the attempt to induce a safe and efficacious immune response [141].

There are currently approximately 28 RSV vaccines and antibodies in preclinical development and another 17 in clinical development (Fig. 2) [142, 143]. RSV vaccine development is a high priority in global healthcare. Whilst no RSV vaccine has been licensed to date, the WHO estimates that RSV vaccination will be available in the next 5-10 years [30].

\section{Target Populations for RSV Vaccines}

There are three potential target populations for RSV vaccines when considering RSV LRTI in pediatric populations, namely young infants ( $<6$ months of age), young children ( $>6$ months of age), and pregnant women [144]. Due to the salient differences between these target populations, vaccine safety and efficacy concerns, as well as vaccine strategies, should be different. Therefore, there are opportunities for more than one type of vaccine, and choosing the target population best suited for a given vaccine is critical to the vaccine candidates' chances for success [141].

Among the candidates in advanced clinical trials, nanoparticle and subunit vaccines are the most promising for pregnant women, whereas live-attenuated, vector-based and subunit vaccines are those that appear optimal for the pediatric population [142, 145]. Subunit vaccines consist of purified proteins, ultimately aiming to induce high-affinity, neutralizing antibodies, and to facilitate cross-priming. Subunit and particle-based vaccines are currently in phase 2 and phase 3 clinical trials, respectively (Fig. 2) [143].

Infants and Young Children There is general consensus that focus should be placed on infants in their first 6 months of life, when the risk of severe RSV-associated respiratory disease is highest [146]. However, young infants have protective maternal neutralizing antibodies that are known to suppress the development of serum and antibody responses [145]. Additionally, researchers are cautious in conducting RSV vaccine studies in young infants due to the experiences with the formalin-inactivated-RSV vaccine in the 1960s [145]. The severe lung inflammation, worsened disease, and deaths that occurred with some early vaccines raised concerns that other non-replicating RSV vaccines might also predispose infants and RSV-naïve children to aberrant immune responses [146]. Children aged $\geq 6$ months are RSV-naive in most cases and are therefore very similar to young infants; however, they have a more mature immune system, conditioning a reduced susceptibility to RSV complications, and lower levels of maternal antibodies [145].

A number of live-attenuated vaccines have been in phase 1 trials in both RSV seropositive and seronegative infants and children. The 

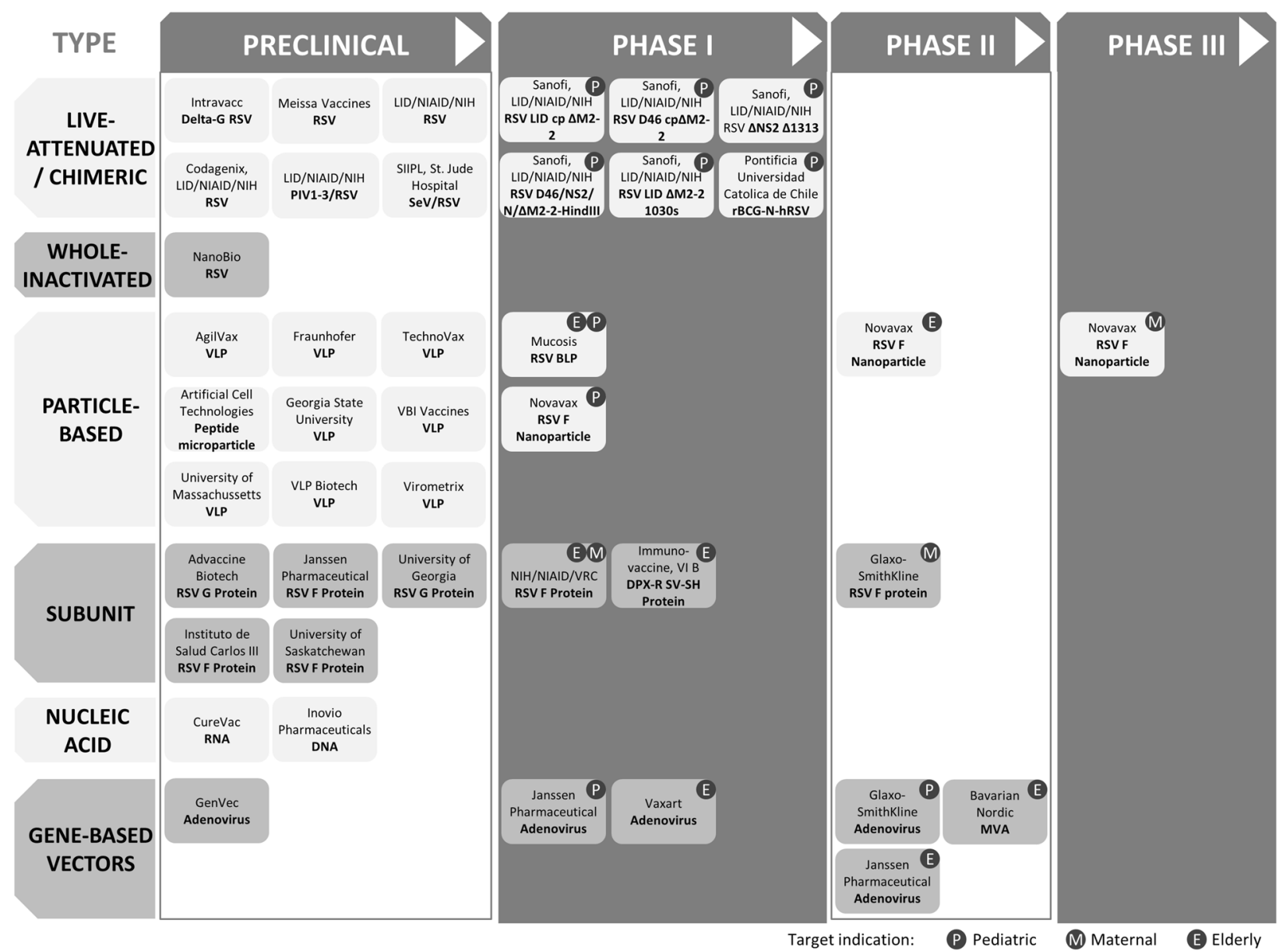

Fig. 2 A snapshot of vaccines to prevent RSVH in preclinical and clinical development worldwide. Adapted from the PATH (formerly the Program for Appropriate Technology in Health) [143]

NIAID are currently investigating the following vaccines in infants and children 6-59 months of age: RSV LID $\triangle \mathrm{M} 2-21030 \mathrm{~s}$ (NCT02952339, NCT02794870) [147, 148]; RSV LID ср $\Delta \mathrm{M} 2-2$ (NCT02948127, NCT02890381) [149, 150]; RSV D46/NS2/N/AM2-2-HindIII (NCT03099291,

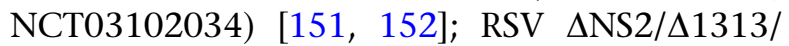
I1314L (NCT03227029, NCT01893554) [153, 154]; RSV D46cp $\Delta \mathrm{M} 2-2$ (NCT02601612) [155]; and RSV 276 (NCT03227029) [153]. Several studies have been completed $[148,150,156-160]$, though few results have been formally published [161]. Advantages of a live-attenuated vaccine approach include that there is little risk of inducing enhanced disease with a subsequent RSV infection, they can be delivered intranasally, they can replicate in the presence of maternal antibodies, and they can broadly stimulate innate, humoral and cellular immunity [142]. Conversely, finding the right balance between safety and immunogenicity, the risk of reversion to wild-type, and producing a stable vaccine virus for mass production are key challenges with this approach [142]. The most promising candidate appears to be RSV LID $\Delta \mathrm{M} 2-2$ [161].

Vector-based approaches have the advantages of avoiding concerns about the level of attenuation of a live-attenuated virus vaccine and the risk of enhanced disease with the subunit approach, while also reducing the likelihood that maternal antibodies would inhibit an immune response in young infants [142]. A chimpanzee-derived adenovirus vector, GSK3389245A (also known as ChAd155-RSV), is currently being investigated in a phase 2 study 
in RSV seropositive infants aged 12-23 months (NCT02927873) [162]. The study is currently recruiting participants [162]. A key challenge to overcome with the vector-based approach is the potential for the development of anti-vector immunity that might limit immune responses to subsequent immunizations [142].

Pregnant Women Maternal immunization could be the best strategy to protect infants during their period of greatest vulnerability to RSV infection and severe disease [145]. Maternal immunization avoids the challenges of direct neonatal immunization at a time when the neonatal immune system shows impaired antibody affinity maturation and less efficient antigen presentation [163]. The aim of vaccinating in pregnancy (in the second or third trimester) is to boost the maternal RSV antibody level available for transplacental transfer above the risk threshold of severe disease and to maintain this putatively protective level for longer-ideally more than at least the first 3 months of life [163]. Indeed, one of the challenges to maternal vaccination is the timing: depending on the time of year in which a third trimester vaccination occurs there is a risk that any conferred immunity may not last throughout the infant's first RSV season [142]. It is expected that passive immunization continues during the breastfeeding period, protecting the infant from early and recurrent infections [164]. However, any vaccine administered to pregnant women will need to meet high tolerability and safety standards [165].

The safety and immunogenicity of a recombinant RSV fusion (F) protein nanoparticle vaccine has been evaluated in healthy adults aged 18-48 years and women of childbearing age. The vaccine, designed for use in the third trimester, appears safe, immunogenic, and reduced RSV infections [166, 167]. A phase 2 study showed that the vaccine reduced RSV infections by $52 \%$ over a 90 -day period in healthy non-pregnant women aged between 18 and 35 years [168]. Phase 3 testing in healthy pregnant women in the third trimester is currently ongoing, with their infants evaluated for RSV LRTI with hypoxemia through the first 90 days of life [169]. Recruitment began in
December 2015, and the study is estimated to be completed in June 2020 (NCT02624947) [169].

A RSV prefusion (F) protein vaccine, GSK3003891A, has recently completed phase 2 testing in healthy women (NCT02753413) [170], although plans for a phase 2 study in pregnant women and infants born to vaccinated mothers have been withdrawn (NCT03191383) [171]. The reason cited for cancelling the study was due to instability of the prefusion (F) antigen during manufacturing. No safety concerns were identified in past or ongoing studies [171]. The NIAID Vaccine Research Center, which first uncovered the crystal structure of the RSV prefusion F protein, has designed a stabilized RSV prefusion F protein vaccine (DS-Cav1) that is stabilized as a trimeric subunit vaccine. DS-Cav1 is currently being evaluated in healthy adults (NCT03049488) [172]. DS-Cav1 is a very promising candidate vaccine for maternal immunization.

\section{Other Vaccine Candidates}

Other promising vaccine candidates, which have been assessed in phase 1 studies in older adults, include: Ad26.RSV.FA2, a stabilized prefusion $\mathrm{F}$ protein expressed in a replication incompetent serotype 26 adenovirus vector (NCT02561871, NCT02440035) [173-175]; and a universal RSV vaccine designed to induce protective immune responses against both subtypes $\mathrm{A}$ and $\mathrm{B}, \mathrm{MVA}-\mathrm{BN}-\mathrm{RSV}$, a recombinant modified Vaccinia Ankara vector encoding for the $\mathrm{F}, \mathrm{GA} / \mathrm{GB}, \mathrm{N}$ and $\mathrm{M} 2$ proteins (NCT02419391, NCT02873286) [176, 177]. Whether these vaccine candidates move successfully through the licensing pathway into pregnant women or children remains to be seen.

Finally, it remains to be established if a combined strategy of maternal and infant immunization will need to be deployed to reduce morbidity and mortality from RSV disease globally [163].

\section{Advances in Prophylaxis}

Antibodies Prophylaxis remains a key strategy to prevent RSV LRTI, and there have been 


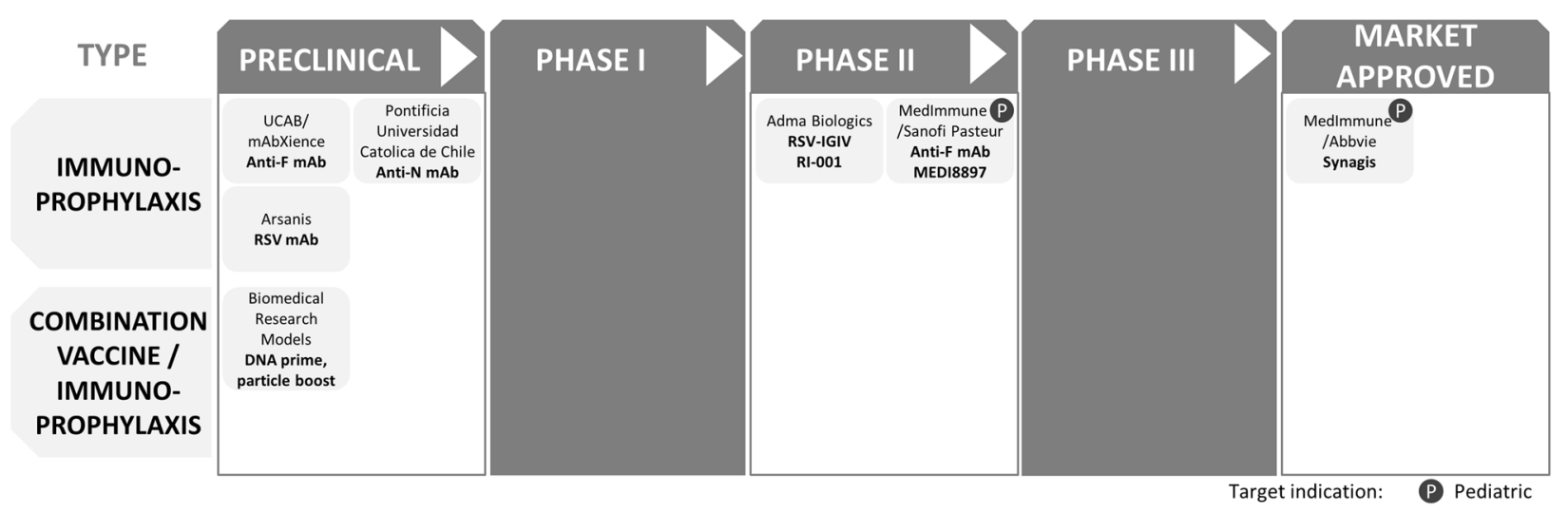

Fig. 3 A snapshot of monoclonal antibodies to prevent RSVH in preclinical and clinical development worldwide. Adapted from the PATH (formerly the Program for Appropriate Technology in Health) [143]

continuous efforts at identifying compounds that could effectively decrease hospitalization rates and disease severity $[145,178]$. The previous success of monoclonal antibodies, such as palivizumab, has promoted research into new monoclonal RSV therapies with improved capacity to block the fusion (F) protein (Fig. 3) $[142,143,178]$. Two of the most promising candidates are described below.

MEDI8897 This investigational, recombinant,

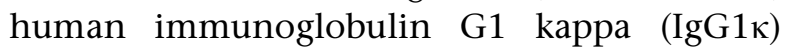
monoclonal antibody that targets the prefusion conformation of the RSV F protein is under clinical development for the prevention of RSV LRTI in infants [179]. MEDI8897 provides a potential opportunity to protect all infants from RSV disease, irrespective of comorbidities, based on an increased potency and extended half-life that supports once-per-RSV season dosing $[179,180]$. It has received fast-track designation for continuing assessment by the FDA.

A phase 1, first-in-human, placebo-controlled study evaluated the pharmacokinetics and safety profile of MEDI8897 in 136 healthy adults as a prelude to a clinical study in infants [179]. Patients were randomized to receive a single dose of MEDI8897 $(n=102)$ or placebo $(n=34)$ in 1 of 5 cohorts $(300,1000$, or $3000 \mathrm{mg}$ IV or 100 or $300 \mathrm{mg}$ IM) and were followed for 360 days. The mean half-life of MEDI8897 was 85-117 days across dose groups, and bioavailability after 300-mg IM dose administration was $77 \%$. Time to maximum concentration following IM dosing was 5-9 days. Antidrug antibody responses were detected in a similar proportion of placebo (15.2\%) and MEDI8897 (13.7\%) recipients. The safety profile of MEDI8897 was similar to placebo. These preliminary results support clinical studies of the IM administration of a single dose of MEDI8897 in the target population of infants to provide protection for the duration of the RSV season [179]. Based upon analysis of interim data from the phase 1 study, a separate phase $2 \mathrm{~b}$ clinical study is currently assessing MEDI8897 in healthy preterm infants who are between 29 and 35 wGA and entering their first RSV season (NCT02878330) [181]. It is expected that results of the trial will be available in 2018 .

RI-001 A phase 2 study is evaluating the safety and efficacy of RI-001, an RSV-IGIV, for the prevention of LRTIs in pediatric immunocompromised patients identified as being infected with RSV in the upper respiratory tract (NCT00632463) [182]. Administration of RI-001 on a compassionate use basis to 15 immunocompromised patients (aged 2 months to 71 years; four $\leq 2$ years) with RSV LRTI, who had either failed conventional therapy or had significant risk of progression, was shown to be well tolerated and to result in significant increases in serum-neutralizing antibody titers to RSV [183]. Eleven of the 15 patients (73.3\%) improved following treatment and were discharged from hospital [183]. 
REGN2222 Another monoclonal antibody directed against the RSV F protein, which was in phase 3 development, suptavumab (REGN2222), recently failed to meet its primary endpoint of preventing medically-attended RSV infections in preterm $(<36$ wGA $)$ infants $\leq 6$ months and has been discontinued from clinical development [184]. The doubleblind, placebo-controlled global Phase 3 NURSERY study randomized 1149 healthy pre-term infants to one of three study groups in a 1:1:1 ratio: suptavumab $30 \mathrm{mg} / \mathrm{kg}$ as a single dose; suptavumab $30 \mathrm{mg} / \mathrm{kg}$ administered as two doses 8 weeks apart; or placebo [184, 185]. The primary endpoint was defined as requiring hospitalization and/or sought medical care for a centrally-adjudicated RSV infection assessed at Day 150 . To date, no data from the study have been presented.

TRL3D3 Prior to this anti-G protein antibody, all previous monoclonal antibodies were directed against the $\mathrm{F}$ protein. In animal models, TLR3D3 demonstrated a hundredfold greater efficacy than palivizumab in ameliorating airway inflammation, despite being a non-neutralizing antibody [186]. It is possible that this anti-G antibody could be used as a potential treatment of RSV.

\section{Therapeutic Drugs to Treat RSV Infection}

Several drugs have been identified for treating RSV infection, either by preventing the entry of the virus into target cells or by preventing replication or assembly of viral particles. A number of these molecules are currently in (advanced) preclinical or clinical development (Table 5) [187]. Recent efforts to develop RSV antiviral drugs have focused primarily on fusion inhibitors or virus gene silencing [144]. So far, several small-molecule RSV entry inhibitors targeting the $\mathrm{F}$ protein have been identified [187]. Encouraging results from a number of clinical studies undertaken in the last 5 years [188-191] have increased optimism that a clinically effective antiviral therapy targeted at high-risk groups may be on the horizon and could become available for clinical use within a few years [192, 193].
Table 5 Drug candidates for treating RSV disease $[187,215]$

\begin{tabular}{ll}
\hline Fusion inhibitors & GS-5806, MDT-637 (VP- \\
& 14637); JNJ-2408068 (R- \\
& 170591); TMC353121; \\
& BMS-433771; BTA-C585; \\
& P13 and C15; JNJ- \\
& $\mathbf{5 3 7 1 8 6 7 8 ; ~ A K - 0 5 2 9 ; ~ R F I - ~}$ \\
& $\mathbf{6 4 1}$ \\
& ALX-0171 \\
& \\
Single domain, trivalent & \\
antibody fragment & \\
derived from Camelidae & \\
(Nanobody) & JNJ-64041575 ; BI-D; AZ- \\
L ("large”)-protein & 27 \\
inhibitors & RSV604 \\
N-protein targeting RSV & \\
inhibitor & \\
Other potential targets include: N-P protein-protein \\
interaction; SH-protein; M2-1 protein
\end{tabular}

One of the most promising candidates is ALX-0171, an inhaled trimeric Nanobody that binds to the RSV F protein, which has shown positive results in a phase $1 / 2$ a study in children hospitalized with RSV infection (NCT02309320) [194, 195]. In this study, 53 children, aged 1-24 months, were administered ALX-0171 or placebo once per day for 3 consecutive days [196]. No treatment-related serious adverse events were reported (primary endpoint), and ALX-0171 was show to have a rapid effect on viral replication (decrease vs. placebo seen after first dose) [196]. This has led to the on-going phase 2b RESPIRE dose-ranging, efficacy study of ALX-0171 (NCT02979431) [197, 198]. In this randomized, double-blind, placebo-controlled, multicenter study, three different doses of inhaled ALX-0171, administered once daily for 3 consecutive days, will be assessed in approximately 180 infants (aged 1-24 months) hospitalized with RSV LRTI. The primary endpoint is to evaluate the anti-viral effect of treatment (time for viral load to drop below assay 
quantification limit in nasal swabs specimens), with topline results expected in the second half of 2018 [197, 198].

GS-5806 (Presatovir), an inhibitor that blocks viral-envelope fusion with the host-cell membrane, was the first of the orally available drug candidates to complete a phase 2 clinical trial [188]. Among the 54 healthy adults infected with RSV, treatment with GS-5806 was shown to reduce the viral load $(P<0.001)$ and severity of symptom scores $(P=0.005)$ versus placebo [188]. Further phase 2 studies in hospitalized adult patients naturally infected with RSV (NCT02135614) [199], in lung transplant recipients with RSV infection (NCT02534350) [200], and in HSCT recipients with RSV infection (NCT02254408, NCT02254421) [201, 202] have all been completed with full publication of the results awaited. No studies in infants and children are currently ongoing.

Other fusion inhibitors in clinical trials include AK-0529, JNJ-53718678, and BTA-C585. AK-0529, which have been studied in healthy adults [203] and are currently recruiting for a phase 2 study in infants hospitalized with RSV infection (NCT02654171) [204]. A phase 2 study of JNJ-53718678 has been completed in healthy adult participants infected with RSV and showed a reduced viral load and disease severity and duration versus placebo [205]. A phase 1 study in RSVH infants, however, was suspended due to health authority feedback regarding drug formulation (NCT02593851) [206]. BTA-C585 has been investigated in phase 1 (NCT02558413, NCT02668367) [207, 208] and 2 (NCT02718937) [209] studies in healthy adult volunteers, though no data have yet been reported.

Another promising therapeutic candidate is the oral RSV replication inhibitor JNJ64041575 (lumicitabine). Results from a phase 2 RSV challenge study in adults $(n=62)$ have been reported, with the time to non-detectability on polymerase-chain-reaction assay $(P<0.001)$, the peak viral load $(P \leq 0.001)$, the area under the curve (AUC) for symptom score $(P<0.05)$, and the AUC for mucus weight lower in all groups receiving JNJ64041575 than in the placebo group [210]. Ongoing studies include a phase 2 study in infants and children (28 days-36 months) hospitalized with RSV infection (NCT03333317) [211], a phase 2 study in adults hospitalized with RSV infection (NCT02935673) [212], and a phase 1 study in infants hospitalized with RSV infection (NCT02202356) [213]. A long-term follow-up of the phase 2 study in infants and children (NCT03333317) is planned to evaluate the subsquent impact of JNJ64041575 on the incidence of asthma and wheezing in these children (NCT03332459) [214].

\section{Limitations}

The most significant limitation is the lack of available therapies and interventions for RSV despite decades of research. While there is a strong body of evidence for palivizumab in the key indicated groups (preterm, CLD/BPD, $\mathrm{CHD),} \mathrm{more} \mathrm{data} \mathrm{in} \mathrm{other} \mathrm{high} \mathrm{risk} \mathrm{populations,}$ such as those with Down syndrome or neurological disorders, would be welcome. 
Key statements/findings

Level of

evidence $^{\mathrm{a}}$

\section{Palivizumab}

Currently, the only product licensed for prophylaxis against RSV

Level 1 studies: 5

Preterm infants $<35$ wGA: 68\% (range 64-100\%) reduction in RSVH (absolute risk reduction:

Risk of bias ${ }^{\mathrm{b}}$ : low $0.2-14.7 \%)$

Quality ${ }^{\mathrm{c}}$ : high

Children with CLD/BPD: 65\% (range 38-72\%) reduction in RSVH (absolute risk reduction:

$$
\text { 4.9-14.2\%) }
$$

Children with CHD: 53\% (range 45-58\%) reduction in RSVH (absolute risk reduction: 4.4-4.6\%)

Limited data in other comorbidities

Significantly reduced subsequent wheezing episodes

Level 1 studies: 1

Risk of bias ${ }^{\mathrm{b}}$ : low

Quality ${ }^{c}$ : high

Ribavirin

Licensed for treatment of severe RSV infection

Level 1 studies: 4

Lack of evidence supporting its efficacy and concerns over toxicity

Risk of bias ${ }^{\mathrm{b}}$ : unclear

Quality: low

Strongest evidence in immunocompromised infants

Future therapies

There are currently around 28 RSV vaccines in preclinical development and WHO estimates the availability of an RSV vaccine within 5-10 years

Nanoparticle and subunit vaccines are the most promising for pregnant women, whereas live- $\quad$ N/A attenuated, vector-based and subunit vaccines are optimal for the pediatric population

Several new antibodies targeting the RSV fusion (F) protein are showing promise (e.g. MEI8897) and N/A entering phase 3 trials

Recent efforts to develop RSV antiviral drugs have focused primarily on fusion inhibitors or virus gene N/A silencing; a number are in development and could become available for clinical use within a few years 
Key statements/findings

Level of evidence ${ }^{a}$

Key areas for research

1. Currently approved therapies

More up-to-date research and published, prospective RCTs are needed to determine:

The effectiveness of palivizumab in reducing RSVH and improving outcomes in children with underlying medical conditions, such as Down syndrome, cystic fibrosis, congenital airway anomalies, immunocompromising or neuromuscular disease

The ultimate impact of palivizumab on longer-term sequelae, such as recurrent wheezing

2. Future therapies for prevention and treatment

Continued research is needed on:

Receptive strategies, such as pre- versus post-natal prophylaxis

Establishing whether there is a causal link between RSV infection and asthma, possibly via a follow-on to a phase 3 vaccine or prophylaxis trial

The optimal timing of therapy with antiviral drugs

Whether the combination of antiviral drugs and immunomodulatory therapies might improve outcomes, as suggested by Prince et al. [216]

$N / A$ not applicable, $R S V H$ respiratory syncytial virus hospitalization, $R C T$ randomized controlled trial

a CEBM) Levels of Evidence [31,32] where Level $1=$ RCTs

b Cochrane risk of bias assessment [34], where low $=$ average of 5/7 domains assessed as low risk of bias, high $=$ average of $5 / 7$ domains assessed as high risk of bias, and unclear for scores inbetween (see online supplementary material for full breakdown)

c Average Jadad score [33], where $\geq 3=$ high quality (see online supplementary material for full breakdown)

\section{CONCLUSION}

Since the failure of early vaccines and the risk of adverse events associated with IGIV immunotherapy, passive immunity with palivizumab has been the mainstay of RSV prophylaxis. The available evidence supports the effectiveness and safety of palivizumab, particularly in high-risk groups, such as preterm infants and those with BPD/CLD and CHD. More evidence is required for palivizumab in certain high-risk populations, such as those with cystic fibrosis, and there remains an unmet need when considering that the majority of RSVHs occur in children born at term without comorbidities.

Prenatal maternal immunization is a potential avenue for infant prophylaxis against RSV, but progress on this will be slowed by the stringent safety standards necessary for any drug aimed toward pregnant women. Likewise, development of new preventive therapies aimed at infants will require rigorous evaluation. That said, there are several promising vaccines and monoclonal antibody compounds in early-stage testing and it is anticipated that new, effective therapies will become available in the next 5 years or so. It is hoped that these new therapies and ongoing research will result in a reduced burden of disease for what currently remains one of the leading causes of childhood hospitalization worldwide.

\section{ACKNOWLEDGEMENTS}

Funding. Dr Joanne Smith, Julie Blake (Reviewers 1 and 2) and Dr Barry Rodgers-Gray (Reviewer 3), from Strategen Limited, 
undertook the systematic review following the protocol approved by the authors. AbbVie provided funding to Strategen to undertake the systematic review. All named authors meet the International Committee of Medical Journal Editors (ICMJE) criteria for authorship for this manuscript, take responsibility for the integrity of the work as a whole, and have given final approval to the version to be published. Editorial assistance in the preparation of this manuscript was provided by Julie Blake and Barry Rodgers-Gray. Julie Blake and Barry RodgersGray developed a first draft of the manuscript, based on the results of the systematic review and input/approval from all authors, which was initially edited by Xavier Carbonell-Estrany and Eric Simões and then circulated among the other authors for input, further edits and subsequent approval. Support for this assistance was funded by AbbVie. AbbVie had the opportunity to review and comment on the completed manuscript but final editorial control rested fully with the authors. AbbVie also funded the article processing charges associated with this article.

Disclosures. Louis Bont has regular interaction with pharmaceutical and other industrial partners. He has not received personal fees or other personal benefits. UMCU has received major funding ( $>€ 100,000$ per industrial partner) for investigator initiated studies from AbbVie, MedImmune, Janssen, the Bill and Melinda Gates Foundation and MeMed Diagnostics. UMCU has received minor funding participation in trials by Regeneron and Janssen since 2015 (total annual estimate less than $€ 20,000)$. He received minor funding for consultation and invited lectures by AbbVie, MedImmune, Ablynx, Bavaria Nordic, MabXience, Novavax, Janssen (total annual estimate less than $€ 20,000$ ). Paul Checchia has acted as an expert advisor and speaker for AbbVie and has received honoraria in this regard. He has also received research grant funding from AstraZeneca. Brigitte Fauroux has received compensation as a neonatology board member from AbbVie. Josep Figueras-Aloy has acted as an expert advisor and speaker for AbbVie and has received honoraria in this regard. Paolo
Manzoni has acted as a speaker for AbbVie and as an expert advisor for AbbVie, TEVA, Medimmune, AstraZeneca, Janssen, and has received honoraria in this regard. Bosco Paes has received research funding from AbbVie Corporation and compensation as an advisor or lecturer from AbbVie and MedImmune. Eric Simões has received grant funding to his institution from Medimmune, Regeneron and Glaxo Smith Kline. Xavier Carbonell-Estrany has acted as an expert advisor and speaker for AbbVie and has received honoraria in this regard.

Compliance with Ethics Guidelines. The analysis in this article is based on previously published studies and does not involve any new studies of human or animal subjects performed by any of the authors.

Data Availability. All data generated or analyzed during this study are included in this published article/as supplementary information files.

Open Access. This article is distributed under the terms of the Creative Commons Attribution-NonCommercial 4.0 International License (http://creativecommons.org/licenses/ by-nc/4.0/), which permits any noncommercial use, distribution, and reproduction in any medium, provided you give appropriate credit to the original author(s) and the source, provide a link to the Creative Commons license, and indicate if changes were made.

\section{REFERENCES}

1. Shi T, McAllister DA, O'Brien KL, Simoes EAF, Madhi SA, Gessner BD, et al. Global, regional, and national disease burden estimates of acute lower respiratory infections due to respiratory syncytial virus in young children in 2015: a systematic review and modelling study. Lancet. 2017;390:946-58.

2. Stein RT, Bont LJ, Zar H, Polack FP, Park C, Claxton $\mathrm{A}$, et al. Respiratory syncytial virus hospitalization and mortality: systematic review and meta-analysis. Pediatr Pulmonol. 2017;52:556-69.

3. Bont L, Checchia PA, Fauroux B, Figueras-Aloy J, Manzoni P, Paes B, et al. Defining the epidemiology 
and burden of severe respiratory syncytial virus infection among infants and children in western countries. Infect Dis Ther. 2016;5:271-98.

4. Glezen WP, Taber LH, Frank AL, Kasel JA. Risk of primary infection and reinfection with respiratory syncytial virus. Arch Pediatr Adolesc Med. 1986;140:543-6.

5. Figueras-Aloy J, Manzoni P, Paes B, Simões EAF, Bont L, Checchia PA, et al. Defining the risk and associated morbidity and mortality of severe respiratory syncytial virus infection among preterm infants without chronic lung disease or congenital heart disease. Infect Dis Ther. 2016;5:417-52.

6. Paes B, Fauroux B, Figueras-Aloy J, Bont L, Checchia PA, Simões EAF, et al. Defining the risk and associated morbidity and mortality of severe respiratory syncytial virus infection among infants with chronic lung disease. Infect Dis Ther. 2016;5:453-71.

7. Checchia PA, Paes B, Bont L, Manzoni P, Simões EAF, Fauroux B, et al. Defining the risk and associated morbidity and mortality of severe respiratory syncytial virus infection among infants with congenital heart disease. Infect Dis Ther. 2017;6:37-56.

8. Manzoni P, Figueras-Aloy J, Simões EAF, Checchia PA, Fauroux B, Bont L, et al. Defining the incidence and associated morbidity and mortality of severe respiratory syncytial virus infection among children with chronic diseases. Infect Dis Ther. 2017;6:383-411.

9. Bloemers BL, van Furth AM, Weijerman ME, Gemke RJ, Broers CJ, van den Ende $K$, et al. Down syndrome: a novel risk factor for respiratory syncytial virus bronchiolitis-a prospective birth-cohort study. Pediatrics. 2007;120:e1076-81.

10. Zachariah P, Ruttenber M, Simões EA. Down syndrome and hospitalizations due to respiratory syncytial virus: a population-based study. J Pediatr. 2012;160:827-31.e1.

11. Kristensen K, Hjuler T, Ravn H, Simões EA, Stensballe LG. Chronic diseases, chromosomal abnormalities, and congenital malformations as risk factors for respiratory syncytial virus hospitalization: a population-based cohort study. Clin Infect Dis. 2012;54:810-7.

12. Murray J, Bottle A, Sharland M, Modi N, Aylin P, Majeed A, et al. Risk factors for hospital admission with RSV bronchiolitis in England: a populationbased birth cohort study. PLoS ONE. 2014;9:e89186.

13. Sorrentino M, Powers T. Effectiveness of palivizumab: evaluation of outcomes from the 1998 to 1999 respiratory syncytial virus season. The Palivizumab
Outcomes Study Group. Pediatr Infect Dis J. 2000;19:1068-71.

14. Garcia DF, Hiatt PW, Jewell A, Schoonover SL, Cron SG, Riggs $M$, et al. Human metapneumovirus and respiratory syncytial virus infections in older children with cystic fibrosis. Pediatr Pulmonol. 2007;42:66-74.

15. Giebels K, Marcotte JE, Podoba J, Rousseau C, Denis $\mathrm{MH}$, Fauvel V, et al. Prophylaxis against respiratory syncytial virus in young children with cystic fibrosis. Pediatr Pulmonol. 2008;43:169-74.

16. Zachariah P, Ruttenber M, Simões EAF. Hospitalizations due to respiratory syncytial virus in children with congenital malformations. Pediatr Infect Dis J. 2011;30:442-5.

17. Chemaly RF, Ghantoji SS, Shah DP, Shah JN, El Taoum KK, Champlin RE, et al. Respiratory syncytial virus infections in children with cancer. J Pediatr Hematol Oncol. 2014;36:e376-81.

18. Campbell AP, Guthrie KA, Englund JA, Farney RM, Minerich EL, Kuypers J, et al. Clinical outcomes associated with respiratory virus detection before allogeneic hematopoietic stem cell transplant. Clin Infect Dis. 2015;61:192-202.

19. Taylor S, Taylor RJ, Lustig RL, Schuck-Paim C, Haguinet F, Webb DJ, et al. Modelling estimates of the burden of respiratory syncytial virus infection in children in the UK. BMJ Open. 2016;6:e009337.

20. Svensson C, Berg K, Sigurs N, Trollfors B. Incidence, risk factors and hospital burden in children under 5 years of age hospitalised with respiratory syncytial virus infections. Acta Paediatr. 2015;104:922-6.

21. Hall CB, Weinberg GA, Blumkin AK, Edwards KM, Staat MA, Schultz AF, et al. Respiratory syncytial virus-associated hospitalizations among children less than 24 months of age. Pediatrics. 2013;132:e341-8.

22. Heikkinen T, Ojala E, Waris M. Clinical and socioeconomic burden of respiratory syncytial virus infection in children. J Infect Dis. 2017;215:17-23.

23. Yoshihara S, Kusuda S, Mochizuki H, Okada K, Nishima S, Simões EA, et al. Effect of palivizumab prophylaxis on subsequent recurrent wheezing in preterm infants. Pediatrics. 2013;132:811-8.

24. Mochizuki H, Kusuda S, Okada K, Yoshihara S, Furuya H, Simões EA, et al. Palivizumab prophylaxis in preterm infants and subsequent recurrent wheezing: six-year follow up study. Am J Respir Crit Care Med. 2017;196:29-38. 
25. Blanken MO, Rovers MM, Molenaar JM, WinklerSeinstra PL, Meijer A, Kimpen JLL, et al. Respiratory syncytial virus and recurrent wheeze in healthy preterm infants. N Engl J Med. 2013;368:1791-9.

26. Wenzel SE, Gibbs RL, Lehr MV, Simoes EA. Respiratory outcomes in high-risk children 7 to 10 years after prophylaxis with respiratory syncytial virus immune globulin. Am J Med. 2002;112:627-33.

27. Sigurs N, Aljassim F, Kjellman B, Robinson PD, Sigurbergsson F, Bjarnason R, et al. Asthma and allergy patterns over 18 years after severe RSV bronchiolitis in the first year of life. Thorax. 2010;65:1045-52.

28. Carbonell-Estrany X, Pérez-Yarza EG, García LS, Guzmán Cabañas JM, Bòria EV, Atienza BB. Longterm burden and respiratory effects of respiratory syncytial virus hospitalization in preterm infantsthe SPRING study. PLoS ONE. 2015;10:e0125422.

29. Fauroux B, Simões EAF, Checchia PA, Paes B, Figueras-Aloy J, Manzoni P, et al. The burden and longterm respiratory morbidity associated with respiratory syncytial virus infection in early childhood. Infect Dis Ther. 2017;6:173-97.

30. World Health Organization. Research needs for the battle against respiratory viruses (BRaVe). Background document 2013. http://www.who.int/ influenza/patient_care/clinical/BRaVe_Research_ Agenda_2013. pdf?ua =1. Accessed 13 Nov 2017.

31. OCEBM Levels of Evidence Working Group. The Oxford 2011 levels of evidence. Oxford Centre for Evidence-Based Medicine. http://www.cebm.net/ index.aspx?o=5653. Accessed 13 Nov 2017.

32. OCEBM Levels of Evidence Working Group. The Oxford 2009 levels of evidence. Oxford Centre for Evidence-Based Medicine http://www.cebm.net/ oxford-centre-evidence-based-medicine-levelsevidencemarch-2009. Accessed 13 Nov 2017.

33. Jadad AR, Moore RA, Carroll D, Jenkinson C, Reynolds DJ, Gavaghan DJ, et al. Assessing the quality of reports of randomized clinical trials: Is blinding necessary? Control Clin Trials. 1996;17:1-12.

34. Higgins JPT, Altman DG. Assessing risk of bias in included studies. In: Higgins JPT editor. Cochrane handbook for systematic reviews of interventions. Chichester: Wiley; 2008. pp 187-241.

35. Viswanathan M, Berkman ND. Development of the RTI item bank on risk of bias and precision of observational studies. J Clin Epidemiol. 2012;65:163-78.

36. Hartling L, Bialy LM, Vandermeer B, Tjosvold L, Johnson DW, Plint AC, et al. Epinephrine for bronchiolitis. Cochrane Database Syst Rev. 2011;6:CD003123.

37. Umoren R, Odey F, Meremikwu MM. Steam inhalation or humidified oxygen for acute bronchiolitis in children up to three years of age. Cochrane Database Syst Rev. 2011;1:CD006435.

38. Enriquez A, Chu IW, Mellis C, Lin WY. Nebulised deoxyribonuclease for viral bronchiolitis in children younger than 24 months. Cochrane Database Syst Rev. 2012;11:CD008395.

39. Roqué i Figuls M, Giné-Garriga M, Rugeles GC, Perrotta C, Vilaró J. Chest physiotherapy for acute bronchiolitis in paediatric patients between 0 and 24 months old. Cochrane Database Syst Rev. 2016;2:CD004873.

40. Shah PS, Ohlsson A, Shah JP. Continuous negative extrathoracic pressure or continuous positive airway pressure compared to conventional ventilation for acute hypoxaemic respiratory failure in children. Cochrane Database Syst Rev. 2013;11:CD003699.

41. Zhang L, Mendoza-Sassi RA, Wainwright C, Klassen TP. Nebulised hypertonic saline solution for acute bronchiolitis in infants. Cochrane Database Syst Rev. 2017;12:CD006458.

42. Farley R, Spurling GK, Eriksson L, Del Mar CB. Antibiotics for bronchiolitis in children under two years of age. Cochrane Database Syst Rev. 2014;10:CD005189.

43. Gadomski AM, Scribani MB. Bronchodilators for bronchiolitis. Cochrane Database Syst Rev. 2014;6:CD001266.

44. Mayfield S, Jauncey-Cooke J, Hough JL, Schibler A, Gibbons K, Bogossian F. High-flow nasal cannula therapy for respiratory support in children. Cochrane Database Syst Rev. 2014;3:CD009850.

45. Rojas-Reyes MX, Granados Rugeles C, Charry-Anzola LP. Oxygen therapy for lower respiratory tract infections in children between 3 months and 15 years of age. Cochrane Database Syst Rev. 2014;12:CD005975.

46. Jat KR, Mathew JL. Continuous positive airway pressure (CPAP) for acute bronchiolitis in children. Cochrane Database Syst Rev. 2015;1:CD010473.

47. Liet JM, Ducruet T, Gupta V, Cambonie G. Heliox inhalation therapy for bronchiolitis in infants. Cochrane Database Syst Rev. 2015;9:CD006915.

48. Liu F, Ouyang J, Sharma AN, Liu S, Yang B, Xiong $\mathrm{W}$, et al. Leukotriene inhibitors for bronchiolitis in infants and young children. Cochrane Database Syst Rev. 2015;3:CD010636. 
49. Ralston SL, Lieberthal AS, Meissner HC, Alverson BK, Baley JE, Gadomski AM, et al. Clinical practice guideline: the diagnosis, management, and prevention of bronchiolitis. Pediatrics. 2014;134:e1474-502.

50. Ricci V, Delgado Nunes V, Murphy MS, Cunningham S, Guideline Development Group and Technical Team. Bronchiolitis in children: summary of NICE guidance. BMJ. 2015;350:h2305.

51. Groothuis JR, Simoes EA, Levin MJ, Hall CB, Long $\mathrm{CE}$, Rodriguez WJ, et al. Prophylactic administration of respiratory syncytial virus immune globulin to high-risk infants and young children. The Respiratory Syncytial Virus Immune Globulin Study Group. N Engl J Med. 1993;329:1524-30.

52. Groothuis JR, Simoes EA, Hemming VG. Respiratory syncytial virus (RSV) infection in preterm infants and the protective effects of RSV immuneglobulin (RSVIG). Respiratory Syncytial Virus Immune Globulin Study Group. Pediatrics. 1995;95:463-7.

53. The PREVENT Study Group. Reduction of respiratory syncytial virus hospitalization among premature infants and infants with bronchopulmonary dysplasia using respiratory syncytial virus immune globulin prophylaxis. Pediatrics. 1997;99:93-9.

54. Simoes EA, Sondheimer HM, Top FH Jr, Meissner HC, Welliver RC, Kramer AA, et al. Respiratory syncytial virus immune globulin for prophylaxis against respiratory syncytial virus disease in infants and children with congenital heart disease. The Cardiac Study Group. J Pediatr. 1998;133:492-9.

55. Redding GJ, Braun S, Mayock D. Impact of respiratory syncytial virus immune globulin in 1996-1997: a local controlled comparison. Arch Pediatr Adolesc Med. 1999;153:503-7.

56. American Academy of Pediatrics Committee on Infectious Diseases, Committee on Fetus and Newborn. Respiratory syncytial virus immune globulin intravenous: indications for use. Pediatrics. 1997;99:645-50.

57. Meissner HC, Groothuis JR, Rodriguez WJ, Welliver RC, Hogg G, Gray PH, et al. Safety and pharmacokinetics of an intramuscular monoclonal antibody (SB 209763) against respiratory syncytial virus (RSV) in infants and young children at risk for severe RSV disease. Antimicrob Agents Chemother. 1999;43:1183-8.

58. Weltzin R, Traina-Dorge V, Soike K, Zhang JY, Mack $P$, Soman $G$, et al. Intranasal monoclonal IgA antibody to respiratory syncytial virus protects rhesus monkeys against upper and lower respiratory tract infection. J Infect Dis. 1996;174:256-61.
59. Johnson S, Oliver C, Prince GA, Hemming VG, Pfarr DS, Wang SC, et al. Development of a humanized monoclonal antibody (MEDI-493) with potent in vitro and in vivo activity against respiratory syncytial virus. J Infect Dis. 1997;176:1215-24.

60. Anderson EJ, Carosone-Link P, Yogev R, Yi J, Simões EAF. Effectiveness of palivizumab in high-risk infants and children. Pediatr Infect Dis J. 2017;36:699-704.

61. The IMpact-RSV Study Group. Palivizumab, a humanized respiratory syncytial virus monoclonal antibody, reduces hospitalization from respiratory syncytial virus infection in high-risk infants. Pediatrics. 1998;102:531-7.

62. Lacaze-Masmonteil T, Truffert P, Pinquier D, Daoud $P$, Goldfarb G, Vicaut E, et al. Lower respiratory tract illness and RSV prophylaxis in very premature infants. Arch Dis Child. 2004;89:562-7.

63. Resch B, Gusenleitner W, Müller WD, Haas J. Observational study of respiratory syncytial virusassociated hospitalizations and use of palivizumab in premature infants aged 29-32 weeks. Eur J Clin Microbiol Infect Dis. 2006;25:120-2.

64. Faldella G, Alessandroni R, Aquilano G, Vandini S, Lanari M, Silvestri M, et al. Hospitalization for lower respiratory tract disease in preterm infants: effects of prophylaxis with palivizumab. J Chemother. 2010;22:30-5.

65. Pedraz C, Carbonell-Estrany X, Figueras-Aloy J, Quero J, IRIS Study Group. Effect of palivizumab prophylaxis in decreasing respiratory syncytial virus hospitalizations in premature infants. Pediatr Infect Dis J. 2003;22:823-7.

66. Figueras-Aloy J, Carbonell-Estrany X, Quero-Jiménez J, Fernández-Colomer B, Guzmán-Cabañas J, Echaniz-Urcelay I, et al. FLIP-2 study: risk factors linked to respiratory syncytial virus infection requiring hospitalization in premature infants born in Spain at a gestational age of 32 to 35 weeks. Pediatr Infect Dis J. 2008;27:788-93.

67. Grimaldi M, Gouyon B, Sagot P, Quantin C, Huet F, Gouyon JB, et al. Palivizumab efficacy in preterm infants with gestational age $<$ or $=30$ weeks without bronchopulmonary dysplasia. Pediatr Pulmonol. 2007;42:189-92.

68. Groothuis JR. Safety of palivizumab in preterm infants 29 to 32 weeks' gestational age without chronic lung disease to prevent serious respiratory syncytial virus infection. Eur J Clin Microbiol Infect Dis. 2003;22:414-7.

69. Ovsyannikov D, Krsheminskaya I, Degtyareva E. Prevention of RSV infection in infants from the 
high-risk groups in Moscow: the first season's results. Eur Respir J. 2012;40:P2740.

70. Turti TV, Baibarina EN, Degtiareva EA, Keshishyan ES, Lobzin YV, Namazova-Baranova LS, et al. A prospective, open-label, non-comparative study of palivizumab prophylaxis in children at high risk of serious respiratory syncytial virus disease in the Russian Federation. BMC Res Notes. 2012;5:484.

71. Oh PI, Lanctôt KL, Yoon A, Lee DS, Paes BA, Simmons BS, et al. Palivizumab prophylaxis for respiratory syncytial virus in Canada: utilization and outcomes. Pediatr Infect Dis J. 2002;21:512-8.

72. Grimaldi M, Gouyon B, Michaut F, Huet F, Gouyon JB, Burgundy Perinatal Network. Severe respiratory syncytial virus bronchiolitis: epidemiologic variations associated with the initiation of palivizumab in severely premature infants with bronchopulmonary dysplasia. Pediatr Infect Dis J. 2004;23:1081-5.

73. Duppenthaler A, Gorgievski-Hrisoho M, Frey U, Aebi C. Two-year periodicity of respiratory syncytial virus epidemics in Switzerland. Infection. 2003;31:75-80.

74. Abbvie. Observational program to assess respiratory syncytial virus (RSV) hospitalization rate in population of children at high-risk of serious RSV illness who received palivizumab immunoprophylaxis (SUNRISE). https://clinicaltrials.gov/ct2/show/ NCT02282982. Accessed 13 Nov 2017.

75. Parnes C, Guillermin J, Habersang R, Nicholes P, Chawla V, Kelly T, et al. Palivizumab prophylaxis of respiratory syncytial virus disease in 2000-2001: results from the palivizumab outcomes registry. Pediatr Pulmonol. 2003;35:484-9.

76. Paes B, Mitchell I, Li A, Lanctôt KL, CARESS Investigators. A comparative study of respiratory syncytial virus (RSV) prophylaxis in premature infants within the Canadian Registry of Palivizumab (CARESS). Eur J Clin Microbiol Infect Dis. 2012;31:2703-11.

77. Frogel M, Nerwen C, Cohen A, VanVeldhuisen P, Harrington M, Boron M, et al. Prevention of hospitalization due to respiratory syncytial virus: results from the Palivizumab Outcomes Registry. J Perinatol. 2008;28:511-7.

78. Notario G, Vo P, Gooch K, Deaton R, Wu X, Harris $\mathrm{B}$, et al. Respiratory syncytial virus-related hospitalization in premature infants without bronchopulmonary dysplasia: subgroup efficacy analysis of the Impact-RSV trial by gestational age group. Pediatric Health Med Ther. 2014;5:43-8.
79. Simoes EA. Immunoprophylaxis of respiratory syncytial virus: global experience. Respir Res. 2002;3:S26-33.

80. Feltes TF, Cabalka AK, Meissner HC, Piazza FM, Carlin DA, Top FH Jr, et al. Palivizumab prophylaxis reduces hospitalization due to respiratory syncytial virus in young children with hemodynamically significant congenital heart disease. J Pediatr. 2003;143:532-40.

81. Medrano López C, García-Guereta L, CIVIC Study Group. Community-acquired respiratory infections in young children with congenital heart diseases in the palivizumab era. Pediatr Infect Dis J. 2010;29:1077-82.

82. Sociedad Española de Cardiología Pediátrica y Cardiopatías Congénitas. http://www.secardioped.org/. Accessed 02 Jan 2018.

83. Cohen SA, Zanni R, Cohen A, Harrington M, VanVeldhuisen $\mathrm{P}$, Boron ML, et al. Palivizumab use in subjects with congenital heart disease: results from the 2000-2004 Palivizumab Outcomes Registry. Pediatr Cardiol. 2008;29:382-7.

84. Simon A, Nowak H, Sterz R. Use of palivizumab in Germany: data from 2002-2007. Klin Padiatr. 2011;223:292-8.

85. Li A, Wang DY, Lanctôt KL, Mitchell I, Paes BA, CARESS Investigators. Comparing first- and secondyear palivizumab prophylaxis in patients with hemodynamically significant congenital heart disease in the CARESS database (2005-2015). Pediatr Infect Dis J. 2017;36:445-50.

86. Mitchell I, Paes BA, Li A, Lanctôt KL, CARESS Investigators. CARESS: the Canadian registry of palivizumab. Pediatr Infect Dis J. 2011;30:651-5.

87. Feltes TF, Sondheimer HM, Tulloh RMR, Harris BS, Jensen KM, Losonsky GA, et al. A randomized controlled trial of motavizumab versus palivizumab for the prophylaxis of serious respiratory syncytial virus disease in children with hemodynamically significant congenital heart disease. Pediatr Res. 2011;70:186-91.

88. Paes B, Mitchell I, Yi H, Li A, Lanctôt KL, CARESS Investigators. Hospitalization for respiratory syncytial virus illness in Down syndrome following prophylaxis with palivizumab. Pediatr Infect Dis J. 2014;33:e29-33.

89. Yi H, Lanctôt KL, Bont L, Bloemers BL, Weijerman $\mathrm{M}$, Broers C, et al. Respiratory syncytial virus prophylaxis in down syndrome: a prospective cohort study. Pediatrics. 2014;133:1031-7. 
90. Paes B, Mitchell I, Li A, Lanctôt KL. Respiratory hospitalizations and respiratory syncytial virus prophylaxis in special populations. Eur J Pediatr. 2012;171:833-41.

91. Manzoni P, Paes B, Lanctôt KL, Dall'Agnola A, Mitchell I, Calabrese S, et al. Outcomes of infants receiving palivizumab prophylaxis for respiratory syncytial virus in Canada and Italy. Pediatr Infect Dis J. 2017;36:2-8.

92. Mitchell I, Paes B, Li A, Lanctot K. RSV hospitalization in cystic fibrosis in the Canadian registry of palivizumab (CARESS) following prophylaxis (2005-2012). Eur Respir J. 2013;42:P3612.

93. Speer ME, Fernandes CJ, Boron M, Groothuis JR. Use of palivizumab for prevention of hospitalization as a result of respiratory syncytial virus in infants with cystic fibrosis. Pediatr Infect Dis J. 2008;27:559-61.

94. Bjornson C, Chan P, Li A, Paes B, Lanctot K, Mitchell I. Palivizumab prophylaxis for respiratory syncytial virus (RSV) in infants with cystic fibrosis (CF) and respiratory illness hospitalizations. Eur Respir J. 2015;46:PA3625.

95. Winterstein AG, Eworuke E, Xu D, Schuler P. Palivizumab immunoprophylaxis effectiveness in children with cystic fibrosis. Pediatr Pulmonol. 2013;48:874-84.

96. Kua KP, Lee SWH. Systematic review of the safety and efficacy of palivizumab among infants and young children with cystic fibrosis. Pharmacotherapy. 2017;37:755-69.

97. Mitchell I, Paes B, Li A, Lanctôt K. RSV hospitalization in infants with neuromuscular disease in the Canadian registry of palivizumab after prophylaxis (2005-2012). Eur Respir J. 2013;42:P4319.

98. Mitchell I, Paes B, Li A, Yi H, Lanctot K. Respiratory syncytial virus (RSV) hospitalization in infants with congenital airway anomalies (CAA) in the Canadian registry of palivizumab (CARESS) after prophylaxis (2005-2012). Eur Respir J. 2014;44:P1259.

99. Drummond D, Thumerelle C, Reix P, Fayon M, Epaud R, Clement A, et al. Effectiveness of palivizumab in children with childhood interstitial lung disease: the French experience. Pediatr Pulmonol. 2016;51:688-95.

100. Mitchell I, Paes B, Wong S, Li A, Lanctot K. Respiratory Illness and Respiratory Syncytial Virus (RSV)Related Hospitalizations (RSVH) in Infants with Congenital Airway Anomalies (CAA) in the CARESS Registry (2005-2015). Am J Respir Crit Care Med. 2017;195:A1196.
101. Chen JJ, Chan P, Paes B, Mitchell I, Li A, Lanctôt KL, et al. Serious adverse events in the canadian registry of children receiving palivizumab (CARESS) for respiratory syncytial virus prevention. PLoS ONE. 2015;10:e0134711.

102. Bonnet D, Prahl R, Fredrick LM, Schulz GA, Notario G, Campbell AL. Retrospective analysis suggests palivizumab prophylaxis is not associated with an increased risk of serious infection, serious arrhythmia or death in pediatric patients $<24$ months of age with hemodynamically significant congenital heart disease. In: Excellence in Pediatrics Conference 30 November-3 December 2011, Istanbul, Turkey, p. 085.

103. Groothuis JR. Safety and tolerance of palivizumab administration in a large Northern Hemisphere trial. Northern Hemisphere Expanded Access Study Group. Pediatr Infect Dis J. 2001;20:628-30.

104. American Academy of Pediatrics Committee on Infectious Diseases; American Academy of Pediatrics Bronchiolitis Guidelines Committee. Updated guidance for palivizumab prophylaxis among infants and young children at increased risk of hospitalization for respiratory syncytial virus infection. Pediatrics. 2014;134:415-20.

105. Ralston SL, Lieberthal AS, Meissner HC, Alverson BK, Baley JE, Gadomski AM, et al. Clinical practice guideline: the diagnosis, management, and prevention of bronchiolitis. Pediatrics. 2014;e1474:e1502 (Pediatrics. 2015;136:782).

106. Goldstein M, Merritt TA, Phillips R, Martin G, Hall $S$, Yogev $R$, et al. National Perinatal Association 2015 Respiratory syncytial virus (RSV) prevention guideline. http://www.neonatologytoday.net/ newsletters/nt-nov14.pdf. Accessed 13 Nov 2017.

107. Robinson JL, Le Saux N, Canadian Paediatric Society, Infectious Diseases and Immunization Committee. Preventing hospitalizations for respiratory syncytial virus infection. Paediatr Child Health. 2015;20:321-6.

108. Bollani L, Baraldi E, Chirico G, Dotta A, Lanari M, Del Vecchio A, et al. Revised recommendations concerning palivizumab prophylaxis for respiratory syncytial virus (RSV). Ital J Pediatr. 2015;41:97.

109. Figueras Aloy J, Carbonell Estrany X, Comité de Estándares de la SENeo. Actualización de las recomendaciones de la Sociedad Española de Neonatología para la utilización del palivizumab como profilaxis de las infecciones graves por el virus respiratorio sincitial. Anales de Pediatría. 2015;82:199.e1-2.

110. Baraldi E, Lanari M, Manzoni P, Rossi GA, Vandini $\mathrm{S}$, Rimini A, et al. Inter-society consensus document 
on treatment and prevention of bronchiolitis in newborns and infants. Ital J Pediatr. 2014;40:65.

111. Wang D, Bayliss S, Meads C. Palivizumab for immunoprophylaxis of respiratory syncitial virus (RSV) bronchiolitis in high-risk infants and young children: a systematic review and additional economic modelling of subgroup analyses. Health Technol Assess. 2011;15:1-124.

112. Munoz FM, Ralston SL, Meissner HC. RSV recommendations unchanged after review of new data. http://www.aappublications.org/news/2017/10/19/ RSV101917. Accessed 13 Nov 2017.

113. van Beek D, Paes B, Bont L. Increased risk of RSV infection in children with Down's syndrome: clinical implementation of prophylaxis in the European Union. Clin Dev Immunol. 2013;2013:801581.

114. American Academy of Pediatrics Committee on Infectious Diseases; American Academy of Pediatrics Bronchiolitis Guidelines Committee. Updated guidance for palivizumab prophylaxis among infants and young children at increased risk of hospitalization for respiratory syncytial virus infection. Pediatrics. 2014;134:e620-38.

115. Carbonell-Estrany X, Simões EAF, Dagan R, Hall CB, Harris B, Hultquist $M$, et al. Motavizumab for prophylaxis of respiratory syncytial virus in high-risk children: a noninferiority trial. Pediatrics. 2009;125:e35-51.

116. O'Brien KL, Chandran A, Weatherholtz R, Jafri HS, Griffin MP, Bellamy T, et al. Efficacy of motavizumab for the prevention of respiratory syncytial virus disease in healthy Native American infants: a phase 3 randomised double-blind placebo-controlled trial. Lancet Infect Dis. 2015;15:1398-408.

117. Ramilo O, Lagos R, Sáez-Llorens X, Suzich J, Wang $\mathrm{CK}$, Jensen $\mathrm{KM}$, et al. Motavizumab treatment of infants hospitalized with respiratory syncytial virus infection does not decrease viral load or severity of illness. Pediatr Infect Dis J. 2014;33:703-9.

118. Simoes EA, Groothuis JR, Carbonell-Estrany X, Rieger $\mathrm{CH}$, Mitchell I, Fredrick LM, et al. Palivizumab prophylaxis, respiratory syncytial virus, and subsequent recurrent wheezing. J Pediatr. 2007;151:34-42.

119. Simões EA, Carbonell-Estrany X, Rieger $\mathrm{CH}$, Mitchell I, Fredrick L, Groothuis JR, et al. The effect of respiratory syncytial virus on subsequent recurrent wheezing in atopic and nonatopic children. J Allergy Clin Immunol. 2010;126:256-62.

120. Simões EAF. Motavizumab, RSV, and subsequent wheezing. Lancet Infect Dis. 2016;16:639-40.
121. Edell D, Bruce E, Hale K, Edell D, Khoshoo V. Reduced long-term respiratory morbidity after treatment of respiratory syncytial virus bronchiolitis with ribavirin in previously healthy infants: a preliminary report. Pediatr Pulmonol. 1998;25:154-8.

122. Edell D, Khoshoo V, Ross G, Salter K. Early ribavarin treatment of bronchiolitis: effect on long-term respiratory morbidity. Chest. 2002;122:935-9.

123. Krilov LR, Mandel FS, Barone SR, Fagin JC. Followup of children with respiratory syncytial virus bronchiolitis in 1986 and 1987: potential effect of ribavirin on long term pulmonary function. The Bronchiolitis Study Group. Pediatr Infect Dis J. 1997;16:273-6.

124. Shah DP, Ghantoji SS, Shah JN, El Taoum KK, Jiang $\mathrm{Y}$, Popat U, et al. Impact of aerosolized ribavirin on mortality in 280 allogeneic haematopoietic stem cell transplant recipients with respiratory syncytial virus infections. J Antimicrob Chemother. 2013;68:1872-80.

125. Anak S, Atay D, Unuvar A, Garipardic M, Agaoglu L, Ozturk G, et al. Respiratory syncytial virus infection outbreak among pediatric patients with oncologic diseases and/or BMT. Pediatr Pulmonol. 2010;45:307-11.

126. Chávez-Bueno S, Mejías A, Merryman RA, Ahmad $\mathrm{N}$, Jafri HS, Ramilo O. Intravenous palivizumab and ribavirin combination for respiratory syncytial virus disease in high-risk pediatric patients. Pediatr Infect Dis J. 2007;26:1089-93.

127. Moler FW, Steinhart CM, Ohmit SE, Stidham GL. Effectiveness of ribavirin in otherwise well infants with respiratory syncytial virus-associated respiratory failure. Pediatric Critical Study Group. J Pediatr. 1996;128:422-8.

128. Guerguerian AM, Gauthier M, Lebel MH, Farrell CA, Lacroix J. Ribavirin in ventilated respiratory syncytial virus bronchiolitis. A randomized, placebocontrolled trial. Am J Respir Crit Care Med. 1999;160:829-34.

129. Law BJ, Wang EE, MacDonald N, McDonald J, Dobson S, Boucher F, et al. Does ribavirin impact on the hospital course of children with respiratory syncytial virus (RSV) infection? An analysis using the pediatric investigators collaborative network on infections in Canada (PICNIC) RSV Database. Pediatrics. 1997;99:E7.

130. Long CE, Voter KZ, Barker WH, Hall CB. Long term follow-up of children hospitalized with respiratory syncytial virus lower respiratory tract infection and randomly treated with ribavirin or placebo. Pediatr Infect Dis J. 1997;16:1023-8. 
131. Meert KL, Sarnaik AP, Gelmini MJ, Lieh-Lai MW. Aerosolized ribavirin in mechanically ventilated children with respiratory syncytial virus lower respiratory tract disease: a prospective, double-blind, randomized trial. Crit Care Med. 1994;22:566-72.

132. Colinas Herrero J, Rodríguez del Corral C, Gómez Sorrigueta P, Fierro Urturi A, Muro Tudelilla J, Jiménez Mena E. Bronchiolitis: revision of 153 cases and comparative study of ribavirin treatment. An Esp Pediatr. 1997;46:143-7.

133. Everard ML, Swarbrick A, Rigby AS, Milner AD. The effect of ribavirin to treat previously healthy infants admitted with acute bronchiolitis on acute and chronic respiratory morbidity. Respir Med. 2001;95:275-80.

134. Sanchez JL, Conway EE, Rubin DH. Ribavirin treatment of respiratory synctial virus infection in neonatal intensive care unit survivors. Clin Intensive Care. 2001;12:169-72.

135. Molinos-Quintana A, Pérez-de Soto C, Gómez-Rosa M, Pérez-Simón JA, Pérez-Hurtado JM. Intravenous ribavirin for respiratory syncytial viral infections in pediatric hematopoietic SCT recipients. Bone Marrow Transpl. 2012;48:265-8.

136. Rodriguez WJ, Arrobio J, Fink R, Kim HW, Milburn C. Prospective follow-up and pulmonary functions from a placebo-controlled randomized trial of ribavirin therapy in respiratory syncytial virus bronchiolitis. Ribavirin Study Group. Arch Pediatr Adolesc Med. 1999;153:469-74.

137. Ohmit SE, Moler FW, Monto AS, Khan AS. Ribavirin utilization and clinical effectiveness in children hospitalized with respiratory syncytial virus infection. J Clin Epidemiol. 1996;49:963-7.

138. Jaberolansar N, Toth I, Young PR, Skwarczynski M. Recent advances in the development of subunitbased RSV vaccines. Expert Rev Vaccines. 2015;15:53-68.

139. Geevarghese B, Simões EA. Antibodies for prevention and treatment of respiratory syncytial virus infections in children. Antivir Ther. 2012;17:201-11.

140. Kim HW, Canchola JG, Brandt CD, Pyles G, Chanock RM, Jensen $\mathrm{K}$, et al. Respiratory syncytial virus disease in infants despite prior administration of antigenic inactivated vaccine. Am J Epidemiol. 1969;89:422-34.

141. Jorquera PA, Anderson L, Tripp RA. Understanding respiratory syncytial virus (RSV) vaccine development and aspects of disease pathogenesis. Expert Rev Vaccines. 2016;15:173-87.
142. Villafana T, Falloon J, Griffin MP, Zhu Q, Esser MT. Passive and active immunization against respiratory syncytial virus for the young and old. Expert Rev Vaccines. 2017;16:1-13.

143. PATH. RSV vaccine snapshot (November 30, 2017). https://www.path.org/publications/files/CVIA_ RSV_snapshot_fs.pdf. Accessed 02 Jan 2018.

144. Broadbent L, Groves $\mathrm{H}$, Shields MD, Power UF. Respiratory syncytial virus, an ongoing medical dilemma: an expert commentary on respiratory syncytial virus prophylactic and therapeutic pharmaceuticals currently in clinical trials. Influ Other Respir Viruses. 2015;9:169-78.

145. Esposito S, Pietro GD. Respiratory syncytial virus vaccines: an update on those in the immediate pipeline. Future Microbiol. 2016;11:1479-90.

146. Higgins D, Trujillo C, Keech C. Advances in RSV vaccine research and development-a global agenda. Vaccine. 2016;34:2870-5.

147. National Institute of Allergy and Infectious Diseases. Evaluating the infectivity, safety, and immunogenicity of a recombinant liveattenuated respiratory syncytial virus vaccine in RSV-seronegative infants and children 6 to 24 months of age. https://clinicaltrials.gov/ct2/show/NCT02952339. Accessed 13 Nov 2017.

148. National Institute of Allergy and Infectious Diseases. Evaluating the infectivity, safety and immunogenicity of a recombinant live-attenuated respiratory syncytial virus vaccine in RSV-seronegative infants 6 to 24 months of age. https:// clinicaltrials.gov/ct2/show/NCT02794870. Accessed 13 Nov 2017.

149. National Institute of Allergy and Infectious Diseases. Infectivity, safety and immunogenicity of a recombinant live-attenuated respiratory syncytial virus vaccine (RSV LID cp $\Delta \mathrm{M} 2-2$ ) in RSV-seronegative infants and children 6 to 24 months of age. https://clinicaltrials.gov/ct2/show/NCT02948127. Accessed 13 Nov 2017.

150. National Institute of Allergy and Infectious Diseases. Evaluating the infectivity, safety and immunogenicity of a recombinant liveattenuated respiratory syncytial virus vaccine (RSV LID cp $\Delta \mathrm{M} 2-2)$ in RSV-seronegative infants 6 to 24 months of age. https://clinicaltrials.gov/ct2/show/ NCT02890381. Accessed 13 Nov 2017.

151. National Institute of Allergy and Infectious Diseases. Infectivity, safety and immunogenicity of a recombinant live-attenuated respiratory syncytial virus vaccine (D46/NS2/N/AM2-2-HindIII) in RSVseronegative infants and children 6 to 24 months of 
age. https://clinicaltrials.gov/ct2/show/ NCT03099291. Accessed 13 Nov 2017.

152. National Institute of Allergy and Infectious Diseases. Evaluating the infectivity, safety, and immunogenicity of a single dose of a recombinant live-attenuated respiratory syncytial virus vaccine (D46/NS2/N/AM2-2-HindIII) in RSV-seronegative infants 6 to 24 months of age. https://clinicaltrials. gov/ct2/show/NCT03102034. Accessed 13 Nov 2017.

153. National Institute of Allergy and Infectious Diseases. Evaluating the Infectivity, Safety, and Immunogenicity of the Recombinant Live-Attenuated Respiratory Syncytial Virus Vaccines RSV $\Delta \mathrm{NS} 2 / \Delta 1313 / \mathrm{I} 1314 \mathrm{~L}$ or RSV 276 in RSV-Seronegative Infants 6 to 24 Months of Age. https:// clinicaltrials.gov/ct2/show/NCT03227029. Accessed 13 Nov 2017.

154. National Institute of Allergy and Infectious Diseases. Evaluating the Safety and Immune Response to a Single Dose of a Respiratory Syncytial Virus (RSV) Vaccine in Infants and Children. https:// clinicaltrials.gov/ct2/show/NCT01893554. Accessed 13 Nov 2017.

155. National Institute of Allergy and Infectious Diseases. Safety and Immunogenicity of the RSV D46cp $\Delta \mathrm{M} 2-2$ Vaccine in RSV-Seropositive Children and RSV-Seronegative Infants and Children. https:// clinicaltrials.gov/ct2/show/NCT02601612. Accessed 02 Jan 2018.

156. National Institute of Allergy and Infectious Diseases. Safety and immune response to a live-attenuated respiratory syncytial virus vaccine in RSVSeronegative Infants and Children. https:// clinicaltrials.gov/ct2/show/NCT02040831. Accessed 14 Nov 2017.

157. National Institute of Allergy and Infectious Diseases. Safety and immune response to a live-attenuated respiratory syncytial virus (RSV) vaccine in RSV-seronegative infants and children. https:// clinicaltrials.gov/ct2/show/NCT02237209. Accessed 14 Nov 2017.

158. National Institute of Allergy and Infectious Diseases. Evaluating the safety and immune response to a single dose of a respiratory syncytial virus (RSV) vaccine in RSV-seronegative infants and children. https://clinicaltrials.gov/ct2/show/NCT01852266. Accessed 14 Nov 2017.

159. National Institute of Allergy and Infectious Diseases. Evaluating the safety and immune response to a single dose of a respiratory syncytial virus (RSV) vaccine. https://clinicaltrials.gov/ct2/show/ NCT01968083. Accessed 14 Nov 2017.
160. National Institute of Allergy and Infectious Diseases. Evaluating the safety and immune response to a respiratory syncytial virus (RSV) vaccine in adults, RSV-seropositive children, and RSVseronegative infants and children. https:// clinicaltrials.gov/ct2/show/NCT01459198. Accessed 14 Nov 2017.

161. Karron RA, Luongo C, Thumar B, Loehr KM, Englund JA, Collins PL, et al. A gene deletion that upregulates viral gene expression yields an attenuated RSV vaccine with improved antibody responses in children. Sci Transl Med. 2015;7:312ra175.

162. GlaxoSmithKline. RSV investigational vaccine in RSV-seropositive infants aged 12 to 23 months. https://clinicaltrials.gov/ct2/show/NCT02927873. Accessed 14 Nov 2017.

163. Saso A, Kampmann B. Vaccination against respiratory syncytial virus in pregnancy: a suitable tool to combat global infant morbidity and mortality? Lancet Infect Dis. 2016;16:e153-63.

164. Espinoza JA, Bueno SM, Riedel CA, Kalergis AM. Induction of protective effector immunity to prevent pathogenesis caused by the respiratory syncytial virus. Implications on therapy and vaccine design. Immunology. 2014;143:1-12.

165. Neuzil KM. Progress toward a respiratory syncytial virus vaccine. Clin Vaccine Immunol. 2016;23:186-8.

166. Glenn GM, Smith G, Fries L, Raghunandan R, Lu H, Zhou B, et al. Safety and immunogenicity of a Sf9 insect cell-derived respiratory syncytial virus fusion protein nanoparticle vaccine. Vaccine. 2013;31:524-32.

167. Glenn GM, Fries LF, Thomas DN, Smith G, Kpamegan E, Lu H, et al. A randomized, blinded, controlled, dose-ranging study of a respiratory syncytial virus recombinant fusion (f) nanoparticle vaccine in healthy women of childbearing age. J Infect Dis. 2016;213:411-22.

168. August A, Glenn GM, Kpamegan E, Hickman SP, Jani D, Lu H, et al. A Phase 2 randomized, observerblind, placebo-controlled, dose-ranging trial of aluminum-adjuvanted respiratory syncytial virus $\mathrm{F}$ particle vaccine formulations in healthy women of childbearing age. Vaccine. 2017;35:3749-59.

169. Novavax. A Phase 3, randomized, observer-blind, placebo-controlled, group-sequential study to determine the immunogenicity and safety of a respiratory syncytial virus (RSV) F nanoparticle vaccine with aluminum in healthy third-trimester pregnant women; and safety and efficacy of maternally transferred antibodies in preventing RSV disease in their infants. https://clinicaltrials.gov/ct2/show/ 
NCT02624947?term=novavax\&rank=2. Accessed 14 Nov 2017.

170. GlaxoSmithKline. Safety and reactogenicity study of GlaxoSmithKline (GSK) Biologicals' investigational respiratory syncytial virus (RSV) vaccine (GSK3003891A) in healthy women. https:// clinicaltrials.gov/ct2/show/NCT02753413. Accessed 14 Nov 2017.

171. GlaxoSmithKline. A study to evaluate the safety, reactogenicity and immunogenicity of the GlaxoSmithKline (GSK) Biologicals' respiratory syncytial virus (RSV) investigational vaccine (GSK3003891A) in healthy pregnant women and infants born to vaccinated mothers. https:// clinicaltrials.gov/ct2/show/NCT03191383. Accessed 14 Nov 2017.

172. National Institute of Allergy and Infectious Diseases. Dose, safety, tolerability and immunogenicity of a stabilized prefusion RSV $\mathrm{F}$ subunit protein vaccine, VRC-RSVRGP084-00-VP (DS-Cav1), alone or with alum adjuvant, in healthy adults. https:// clinicaltrials.gov/ct2/show/NCT03049488. Accessed 05 Dec 2017.

173. Crucell Holland BV. A study to evaluate the safety, tolerability and immunogenicity of Ad26.RSV.FA2 followed by Ad35.RSV.FA2 in healthy adult volunteers. https://clinicaltrials.gov/ct2/show/ NCT02561871. Accessed 05 Dec 2017.

174. Crucell Holland BV. A study to evaluate the safety, tolerability and immunogenicity of Ad35.RSV.FA2 regimens boosted with Ad26.RSV.FA2 in healthy adult participants. https://clinicaltrials.gov/ct2/ show/NCT02440035. Accessed 05 Dec 2017.

175. Krarup A, Truan D, Furmanova-Hollenstein P, Bogaert L, Bouchier P, Bisschop IJ, et al. A highly stable prefusion RSV F vaccine derived from structural analysis of the fusion mechanism. Nat Commun. 2015;6:8143.

176. Bavarian Nordic. Trial to evaluate the safety, tolerability and immunogenicity of the recombinant MVA BN ${ }^{\circledR}$ RSV vaccine. https://clinicaltrials.gov/ ct2/show/NCT02419391. Accessed 05 Dec 2017.

177. Bavarian Nordic. RSV-MVA-BN vaccine phase II trial in $\geq 55$ year old adults. https://clinicaltrials.gov/ ct2/show/NCT02873286. Accessed 05 Dec 2017.

178. Rivera CA, Gómez RS, Díaz RA, Céspedes PF, Espinoza JA, González PA, et al. Novel therapies and vaccines against the human respiratory syncytial virus. Expert Opin Investig Drugs. 2015;24:1613-30.

179. Griffin MP, Khan AA, Esser MT, Jensen K, Takas T, Kankam MK, et al. Safety, tolerability, and pharmacokinetics of MEDI8897, the respiratory syncytial virus prefusion f-targeting monoclonal antibody with an extended half-life, in healthy adults. Antimicrob Agents Chemother. 2017;61:e1714-6.

180. Zhu Q, McLellan JS, Kallewaard NL, Ulbrandt ND, Palaszynski S, Zhang J, et al. A highly potent extended half-life antibody as a potential RSV vaccine surrogate for all infants. Sci Transl Med. 2017;9:eaаj1928.

181. Medimmune LLC. A study to evaluate the safety and efficacy of MEDI8897 for the prevention of medically-attended RSV LRTI in healthy preterm infants. https://clinicaltrials.gov/ct2/show/ NCT02878330. Accessed 15 Nov 2017.

182. ADMA Biologics. RI-001 in immunosuppressed respiratory syncytial virus (RSV) infected patients at risk of lower tract RSV illness. https://clinicaltrials. gov/ct2/show/NCT00632463. Accessed 15 Nov 2017.

183. Falsey AR, Koval C, DeVincenzo JP, Walsh EE. Compassionate use experience with high-titer respiratory syncytical virus (RSV) immunoglobulin in RSV-infected immunocompromised persons. Transpl Infect Dis. 2017;19:2.

184. Regeneron Pharmaceuticals. Regeneron to discontinue development of suptavumab for respiratory syncytial virus. http://investor.regeneron.com/ releaseDetail.cfm?releaseid $=1037184$. Accessed 15 Nov 2017.

185. Regeneron Pharmaceuticals. Study to evaluate the efficacy and safety of REGN2222, for the prevention of medically attended RSV (Respiratory Syncytial Virus) infection in preterm infants. https:// clinicaltrials.gov/ct2/show/NCT02325791. Accessed 15 Nov 2017.

186. Han J, Takeda K, Wang M, Zeng W, Jia Y, Shiraishi Y, et al. Effects of anti-g and anti-f antibodies on airway function after respiratory syncytial virus infection. Am J Respir Cell Mol Biol. 2014;51:143-54.

187. Heylen E, Neyts J, Jochmans D. Drug candidates and model systems in respiratory syncytial virus antiviral drug discovery. Biochem Pharmacol. 2017;127:1-12.

188. DeVincenzo JP, Whitley RJ, Mackman RL, ScaglioniWeinlich C, Harrison L, Farrell E, et al. Oral GS-5806 activity in a respiratory syncytial virus challenge study. N Engl J Med. 2014;371:711-22.

189. DeVincenzo J, Lambkin-Williams R, Wilkinson T, Cehelsky J, Nochur S, Walsh E, et al. A randomized, double-blind, placebo-controlled study of an RNAibased therapy directed against respiratory syncytial virus. Proc Natl Acad Sci USA. 2010;107:8800-5. 
190. Devincenzo J, Fathi H, McClure M, Westland C, Chanda S, Lambkin-Williams $\mathrm{R}$, et al. Oral ALS008176, a nucleoside analog, rapidly reduces RSV viral load and clinical disease severity in a healthy volunteer challenge study. Open Forum Infect Dis. 2014;1:S66.

191. Schepens B, Ibañez LI, De Baets S, Hultberg A, Bogaert P, De Bleser P, et al. Nanobodies ${ }^{\circledR}$ specific for respiratory syncytial virus fusion protein protect against infection by inhibition of fusion. J Infect Dis. 2011;204:1692-701.

192. Drysdale SB, Green CA, Sande CJ. Best practice in the prevention and management of paediatric respiratory syncytial virus infection. Ther Adv Infect Dis. 2016;3:63-71.

193. Shook BC, Lin K. Recent advances in developing antiviral therapies for respiratory syncytial virus. Top Curr Chem (Cham). 2017;375:40.

194. Ablynx. Ablynx reports positive top line results for its inhaled anti-RSV nanobody(alx-0171) in a phase i/iia study in infants hospitalised with an RSV infection. https://globenewswire.com/news-release/ 2016/05/03/835709/10162333/en/ABLYNX-REPORTSPOSITIVE-TOP-LINE-RESULTS-FOR-ITS-INHALEDANTI-RSV-NANOBODY-ALX-0171-IN-A-PHASE-I-IIaSTUDY-IN-INFANTS-HOSPITALISED-WITH-AN-RSVINFECTION.html. Accessed 15 Nov 2017.

195. Ablynx. A multicentre study in otherwise healthy infants and toddlers hospitalised for and diagnosed with RSV lower respiratory tract infection to evaluate the safety, tolerability, and clinical activity of ALX-0171. https://clinicaltrials.gov/ct2/show/ NCT02309320. Accessed 15 Nov 2017.

196. Ablynx. Results from the first-in-infant Phase I/IIa study with the anti-RSV Nanobody, ALX-0171. http://www.ablynx.com/uploads/data/files/ablynx alx-0171_first-in-infant\%20study\%20results_ webcast $\% 20$ presentation.pdf. Accessed $1 \overline{5}$ Nov 2017.

197. Ablynx. Ablynx initiates the phase iib "respire" study of its wholly-owned, first-in-class, inhaled anti-RSV nanobody, alx-0171, for the treatment of RSV infections in hospitalised infants. https:// globenewswire.com/news-release/2017/01/11/9051 76/0/en/ABLYNX-INITIATES-THE-PHASE-IIb-RESPIRESTUDY-OF-ITS-WHOLLY-OWNED-FIRST-IN-CLASSINHALED-ANTI-RSV-NANOBODY-ALX-0171-FORTHE-TREATMENT-OF-RSV-INFECTIONS-IN-HOSPI TALISED-INFANTS.html. Accessed 15 Nov 2017.

198. Ablynx. Dose ranging study of ALX-0171 in infants hospitalized for respiratory syncytial virus lower respiratory tract infection (Respire). https:// clinicaltrials.gov/ct2/show/NCT02979431. Accessed 15 Nov 2017.
199. Gilead Sciences. Efficacy, pharmacokinetics, and safety of presatovir in hospitalized adults with respiratory syncytial virus (RSV) infection. https:// clinicaltrials.gov/ct2/show/NCT02135614. Accessed 15 Nov 2017.

200. Gilead Sciences. Presatovir in lung transplant (lt) recipients with respiratory syncytial virus (RSV) infection (RSVAdultLungTx). https://clinicaltrials. gov/ct2/show/NCT02534350. Accessed 15 Nov 2017.

201. Gilead Sciences. Presatovir in hematopoietic cell transplant recipients with respiratory syncytial virus infection of the upper respiratory tract. https:// clinicaltrials.gov/ct2/show/NCT02254408. Accessed 15 Nov 2017.

202. Gilead Sciences. Presatovir in hematopoietic cell transplant recipients with respiratory syncytial virus (RSV) infection of the lower respiratory tract. https://clinicaltrials.gov/ct2/show/NCT02254421. Accessed 15 Nov 2017.

203. Toovey S WJ, Wu J, Wang V, Griffin P, Lau A, Elliott $S$. Safety and pharmacokinetics in healthy volunteers of the anti-RSV antiviral AK0529. In: 1st International Meeting on Respiratory Pathogens Singapore 2015.

204. Ark Biosciences. Viral inhibition in children for treatment of RSV (VICTOR). https://clinicaltrials. gov/ct2/show/NCT02654171. Accessed 15 Nov 2017.

205. Israel S, Rusch S, DeVincenzo J, Boyers A, Fok-Seang J, Huntjens D, et al. Effect of oral JNJ-53718678 (JNJ-678) on disease severity in healthy adult volunteers experimentally inoculated with live respiratory syncytial virus (RSV): a placebo-controlled challenge study. OFID. 2016;1:650.

206. Janssen Sciences Ireland. A study to assess the pharmacokinetics, safety, and tolerability of multiple doses of orally administered JNJ-53718678 in infants hospitalized with respiratory syncytial virus (RSV) infection. https://clinicaltrials.gov/ct2/show/ NCT02593851. Accessed 15 Nov 2017.

207. Biota Pharmaceuticals. Phase 1 safety and pharmacokinetics study of single ascending doses of BTAC585 in healthy volunteers. https://clinicaltrials. gov/ct2/show/NCT02558413. Accessed 15 Nov 2017.

208. Biota Pharmaceuticals. Safety and pharmacokinetics study of multiple ascending doses of BTA-C585 in healthy volunteers. https://clinicaltrials.gov/ct2/ show/NCT02668367. Accessed 15 Nov 2017.

209. Biota Pharmaceuticals. Safety, efficacy and pharmacokinetics of BTA-C585 in a RSV viral challenge 
study. https://clinicaltrials.gov/ct2/show/

NCT02718937. Accessed 15 Nov 2017.

210. DeVincenzo JP, McClure MW, Symons JA, Fathi H, Westland C, Chanda S, et al. Activity of oral ALS008176 in a respiratory syncytial virus challenge study. N Engl J Med. 2015;373:2048-58.

211. Janssen Research and Development, LLC. A Study to evaluate the antiviral activity, clinical outcomes, safety, tolerability, and pharmacokinetics of orally administered lumicitabine (JNJ-64041575) regimens in hospitalized infants and children aged 28 days to 36 months infected with respiratory syncytial virus. https://clinicaltrials.gov/ct2/show/ NCT03333317. Accessed 03 Jan 2018.

212. Janssen Research and Development, LLC. Study to evaluate the antiviral activity, clinical outcomes, safety, tolerability, and pharmacokinetics of orally administered lumicitabine regimens in adult participants hospitalized with respiratory syncytial virus. $\quad$ https://clinicaltrials.gov/ct2/show/ NCT02935673. Accessed 16 Nov 2017.
213. Alios Biopharma. A study of ALS-008176 in infants hospitalized with RSV. https://clinicaltrials.gov/ct2/ show/NCT02202356. Accessed 16 Nov 2017.

214. Janssen Research and Development, LLC. A Longterm Follow-up Study to Evaluate the Impact of Lumicitabine on the Incidence of Asthma and/or Wheezing in Infants and Children With a History of Respiratory Syncytial Virus Infection. https:// clinicaltrials.gov/ct2/show/NCT03332459. Accessed 03 Jan 2018.

215. Detalle L, Stohr T, Palomo C, Piedra PA, Gilbert BE, Mas $V$, et al. Generation and characterization of ALX-0171, a potent novel therapeutic nanobody for the treatment of respiratory syncytial virus infection. Antimicrob Agents Chemother. 2015;60:6-13.

216. Prince GA, Mathews A, Curtis SJ, Porter DD. Treatment of respiratory syncytial virus bronchiolitis and pneumonia in a cotton rat model with systemically administered monoclonal antibody (Palivizumab) and glucocorticosteriod. J Infect Dis. 2000;182:1326-30. 